\title{
Calcineurin Inhibition Causes $\alpha 2 \delta$-1-Mediated Tonic Activation of Synaptic NMDA Receptors and Pain Hypersensitivity
}

\author{
Yuying Huang(黄玉莹), Shao-Rui Chen(陈少瑞), Hong Chen(陈红), Yi Luo(罗艺), and Hui-Lin Pan(潘惠麟) \\ Center for Neuroscience and Pain Research, Department of Anesthesiology and Perioperative Medicine, University of Texas M. D. Anderson Cancer \\ Center, Houston, Texas 77030
}

Calcineurin inhibitors, such as tacrolimus (FK506) and cyclosporine, are widely used as standard immunosuppressants in organ transplantation recipients. However, these drugs can cause severe pain in patients, commonly referred to as calcineurin inhibitor-induced pain syndrome (CIPS). Although calcineurin inhibition increases NMDAR activity in the spinal cord, the underlying mechanism remains enigmatic. Using an animal model of CIPS, we found that systemic administration of FK506 in male and female mice significantly increased the amount of $\alpha 2 \delta$-1-GluN1 complexes in the spinal cord and the level of $\alpha 2 \delta$-1-bound GluN1 proteins in spinal synaptosomes. Treatment with FK506 significantly increased the frequency of mEPSCs and the amplitudes of monosynaptic EPSCs evoked from the dorsal root and puff NMDAR currents in spinal dorsal horn neurons. Inhibiting $\alpha 2 \delta$-1 with gabapentin or disrupting the $\alpha 2 \delta$-1-NMDAR interaction with $\alpha 2 \delta$-1Tat peptide completely reversed the effects of FK506. In $\alpha 2 \delta$-1 gene KO mice, treatment with FK506 failed to increase the frequency of NMDARmediated mEPSCs and the amplitudes of evoked EPSCs and puff NMDAR currents in spinal dorsal horn neurons. Furthermore, systemic administration of gabapentin or intrathecal injection of $\alpha 2 \delta$-1Tat peptide reversed thermal and mechanical hypersensitivity in FK506-treated mice. In addition, genetically deleting GluN1 in dorsal root ganglion neurons or $\alpha 2 \delta$-1 genetic KO similarly attenuated FK506-induced thermal and mechanical hypersensitivity. Together, our findings indicate that $\alpha 2 \delta$-1-bound NMDARs mediate calcineurin inhibitor-induced tonic activation of presynaptic and postsynaptic NMDARs at the spinal cord level and that presynaptic NMDARs play a prominent role in the development of CIPS.

Key words: DRG; DRG neuron; gabapentinoid; neuropathic pain; pregabalin; synaptic plasticity

Significance Statement

Calcineurin inhibitors are immunosuppressants used to prevent rejection of transplanted organs and tissues. However, these drugs can cause severe, unexplained pain. We showed that calcineurin inhibition enhances physical interaction between $\alpha 2 \delta$ 1 and NMDARs and their synaptic trafficking in the spinal cord. $\alpha 2 \delta-1$ is essential for calcineurin inhibitor-induced aberrant activation of presynaptic and postsynaptic NMDARs in the spinal cord. Furthermore, inhibiting $\alpha 2 \delta-1$ or disrupting $\alpha 2 \delta$-1NMDAR interaction reduces calcineurin inhibitor-induced pain hypersensitivity. Eliminating NMDARs in primary sensory neurons or $\alpha 2 \delta-1 \mathrm{KO}$ also attenuates calcineurin inhibitor-induced pain hypersensitivity. This new information extends our mechanistic understanding of the role of endogenous calcineurin in regulating synaptic plasticity and nociceptive transmission and suggests new strategies for treating this painful condition.

Received Feb. 5, 2020; revised Mar. 16, 2020; accepted Mar. 22, 2020

Author contributions: Y.H., S.-R.C., H.C., and Y.L. performed research; Y.H., S.-R.C., Y.L., and H.-L.P. analyzed data; Y.H. and S.-R.C. wrote the first draft of the paper; H.-L.P. designed research; H.-L.P. edited the paper.

This work was supported by National Institutes of Health Grants NS101880 and GM120844, and the N.G. and Helen T. Hawkins Endowment.

The authors declare no competing financial interests.

Correspondence should be addressed to Hui-Lin Pan at huilinpan@mdanderson.org.

https://doi.org/10.1523/JNEUROSCI.0282-20.2020

Copyright $\odot 2020$ the authors

\section{Introduction}

Calcineurin inhibitors, such as tacrolimus (FK506) and cyclosporine, are immunosuppressants widely used to prevent rejection of transplanted organs and tissues. Calcineurin inhibitorinduced pain syndrome (CIPS) is an increasingly recognized severe complication of calcineurin inhibitors that occurs in both solid organ and hematopoietic transplantation recipients (Grotz et al., 2001; Kakihana et al., 2012; Wei et al., 2018). Calcineurin is a $\mathrm{Ca}^{2+} /$ calmodulin-dependent serine/threonine protein phosphatase that modulates many physiologic processes, including ion channel activity and immune function (Tong et al., 1995; 
Denton et al., 1999; Wu et al., 2005). Calcineurin is expressed at high levels in immune $\mathrm{T}$ cells and the nervous system, including the spinal dorsal horn and DRG (Strack et al., 1996; Wu et al., 2005; S. R. Chen et al., 2013; Miletic et al., 2013). Both cyclosporine and FK506 can cause CIPS, common symptoms of which include burning and tingling pain and tactile allodynia (Villaverde et al., 1999; Fujii et al., 2006; Noda et al., 2008; Tasoglu et al., 2016; Wei et al., 2018). However, CIPS remains difficult to treat, and the molecular mechanism of CIPS is still unclear.

The glutamate NMDARs in the spinal dorsal horn play a pivotal role in the development of chronic neuropathic pain (Yamamoto and Yaksh, 1992; H. Y. Zhou et al., 2011). Calcineurin is involved in negative feedback control of NMDAR activity and nociceptive transmission (Tong et al., 1995; Miletic et al., 2013). Although calcineurin inhibition increases presynaptic and postsynaptic NMDAR activity in the spinal dorsal horn (S. R. Chen et al., 2014a; Hu et al., 2014), the signaling mechanism responsible for NMDAR hyperactivity in CIPS remains poorly understood. $\alpha 2 \delta-1$ (encoded by the Cacna2d1 gene), commonly regarded as a $\mathrm{Ca}^{2+}$ channel subunit, is expressed in spinal dorsal horn and DRG neurons (Newton et al., 2001; Cole et al., 2005). In the spinal superficial dorsal horn, $\alpha 2 \delta-1$ is mainly detected at primary afferent central terminals and excitatory neurons (Cole et al., 2005; Taylor and Garrido, 2008). Recent studies reveal that $\alpha 2 \delta-1$ couples to NMDARs and mediates nerve injury- and chemotherapy-induced neuropathic pain (J. Chen et al., 2018; Y. Chen et al., 2019). In addition, gabapentinoids, the $\alpha 2 \delta-1$ inhibitory ligands, reduce pain hypersensitivity by acting on $\alpha 2 \delta$ 1-bound NMDARs independent of $\mathrm{Ca}^{2+}$ channels (J. Chen et al., 2018; Y. Chen et al., 2019; Deng et al., 2019a). Some case reports show that gabapentin and pregabalin can alleviate pain in patients with CIPS (Tasoglu et al., 2016; Udomkarnjananun et al., 2018; Wei et al., 2018). However, the evidence is limited as to whether $\alpha 2 \delta-1$ plays a role in calcineurin inhibitor-potentiated NMDAR activity and pain hypersensitivity.

In the current study, we determined the role of $\alpha 2 \delta-1$ in synaptic NMDAR plasticity in a mouse model of CIPS. We tested the hypothesis that calcineurin inhibition leads to tonic activation of NMDARs at the spinal cord level and pain hypersensitivity by potentiating the $\alpha 2 \delta-1-\mathrm{NMDAR}$ interaction and synaptic trafficking of $\alpha 2 \delta$-1-bound NMDARs. Our findings extend our mechanistic understanding of the role of endogenous calcineurin in regulating synaptic plasticity and nociceptive transmission and suggests new strategies for treating CIPS.

\section{Materials and Methods}

\section{Animal model}

All surgical procedures and protocols were approved by the Institutional Animal Care and Use Committee of the University of Texas M. D. Anderson Cancer Center (Approval \#1174-RN00). Conventional Cacna2d1 KO $\left(\right.$ Cacna2d1 $1^{-l-}$ ) mice were generated as described previously (Fuller-Bicer et al., 2009) and were purchased from Medical Research Council (Stock \#6900; Harwell Didcot). The lack of $\alpha 2 \delta$-1 proteins in Cacna2d1 ${ }^{-/-}$mice has been demonstrated using immunoblotting and radioligand binding (Fuller-Bicer et al., 2009; Luo et al., 2018). Cacna2d1 $1^{-1-}$ and WT Cacna2d1 ${ }^{+/+}$littermates were generated by mating Cacna2d $1^{+/-}$heterozygous C57BL/6 mice.

Grin $1^{\text {flox/flox }}$ mice (stock \#005246) were purchased from The Jackson Laboratory. Advillin ${ }^{\mathrm{Cre} /+}$ mice were kindly provided by Fan Wang (Duke University, Durham, NC) (da Silva et al., 2011). Male Advillin ${ }^{\mathrm{Cre} /+}$ mice were crossed with female Grinl $1^{\text {flox/flox }}$ mice first to obtain male Advillin ${ }^{\mathrm{Cre} /+}$ :: Grin $1^{\text {flox } /+}$ mice, which were crossed again with female Grin $1^{\text {flox/flox }}$ mice to generate $A d v i l l i n{ }^{\mathrm{Cre} /+}:: G r i n 1^{\text {flox/flox }}$ mice, referred to as Grin1-cKO (conditional $\mathrm{KO}$ ) mice (genetic background, C57BL/6). Cre-negative littermates

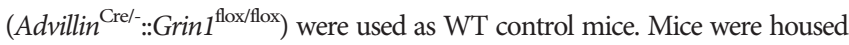
in a pathogen-free facility at no more than 5 per cage on a $12 \mathrm{~h}$ light/dark cycle, with free access to food and water.

Age- and sex-matched adult mice (8-12 weeks old) were used for final experiments. DMSO was used to dissolve FK506, a highly specific calcineurin inhibitor (J. Liu et al., 1991). FK506 was injected intraperitoneally $(3 \mathrm{mg} / \mathrm{kg}$ ) once per day for $7 \mathrm{~d}$. We used this dose because $1-5 \mathrm{mg} /$ kg FK506 inhibits T-cell immune function in mice (Isobe et al., 1997; Whitehouse et al., 2017). Mice in the vehicle control group received DMSO injection in a similar manner. Vehicle- and FK506-treated mice were indistinguishable from one another on the basis of a visual inspection for overt abnormalities and body weights. All electrophysiological, behavioral, and biochemical experiments were conducted 3-5 d after the last FK506 or vehicle injection.

FK506 and gabapentin were obtained from Tocris Bioscience. A peptide mimicking the C-terminal domain (VSGLNPSLWSIFGLQFILLW LVSGSRHYLW) of $\alpha 2 \delta$-1 fused with the cell-penetrating peptide Tat (YGRKKRRQRRR) and a scrambled control peptide (FGLGWQPW SLSFYLVWSGLILSVLHLIRSN) fused with Tat were synthesized by Bio Basic.

\section{Electrophysiological recordings in spinal cord slices}

Mice were anesthetized with 2\%-3\% isoflurane, and the lumbar spinal cord was quickly removed via laminectomy. The animals were then killed via inhalation of $5 \%$ isoflurane followed by rapid decapitation. The spinal cord tissues were immediately placed in ice-cold aCSF (in $\mathrm{mM}$ ) as follows: 234 sucrose, $26 \mathrm{NaHCO}_{3}, 3.6 \mathrm{KCl}, 1.2 \mathrm{NaH}_{2} \mathrm{PO}_{4}, 1.2 \mathrm{MgCl}_{2}, 2.5$ $\mathrm{CaCl}_{2}$, and 25 glucose, oxygenated with $95 \% \mathrm{O}_{2}$ and $5 \% \mathrm{CO}_{2}$. Spinal cord transverse slices were cut at $400 \mu \mathrm{m}$ thick using a vibratome and then incubated in Krebs solution containing (in $\mathrm{mM}$ ) as follows: 117 $\mathrm{NaCl}, 1.2 \mathrm{NaH}_{2} \mathrm{PO}_{4}, 25 \mathrm{NaHCO}_{3}, 3.6 \mathrm{KCl}, 1.2 \mathrm{MgCl}_{2}, 2.5 \mathrm{CaCl}_{2}$, and 11 glucose, presaturated with $95 \% \mathrm{O}_{2}$ and $5 \% \mathrm{CO}_{2}$ at $34^{\circ} \mathrm{C}$ for at least $1 \mathrm{~h}$ before recordings were obtained.

The spinal cord slices were placed in the recording chamber with continuous perfusion of oxygenated Krebs solution $(3 \mathrm{ml} / \mathrm{min})$ at $34^{\circ} \mathrm{C}$ during recording. We recorded lamina II outer neurons identified using infrared illumination and differential interference contrast under a microscope. EPSCs were recorded using whole-cell patch clamp at a holding potential of $-60 \mathrm{mV}$ (S. R. Chen et al., 2014b; Huang et al., 2019). The glass pipette electrode (4-7 M $\Omega$ ) was filled with the internal solution containing the following (in $\mathrm{mM}$ ): $135 \mathrm{~K}$-gluconate, $5 \mathrm{KCl}, 2$ $\mathrm{MgCl}_{2}, 0.5 \mathrm{CaCl}_{2}$, 5 EGTA, 5 HEPES, $0.5 \mathrm{Na}_{2}$-GTP, $5 \mathrm{Mg}$-ATP, and 10 lidocaine N-ethyl bromide (QX314; 280-300 mOsm, pH 7.3). QX314 was included in the pipette recording solution to suppress postsynaptic neuronal firing (D. P. Li et al., 2002; Pan et al., 2002; S. R. Chen et al., 2014a). mEPSCs were recorded in the presence of $0.5 \mu \mathrm{M}$ TTX. In addition, monosynaptic EPSCs were evoked by electrical stimulation $(0.6 \mathrm{~mA}, 0.5 \mathrm{~ms}$, and $0.1 \mathrm{~Hz})$ of the dorsal root to measure glutamate release from primary afferent nerves (H. Y. Zhou et al., 2010; S. R. Chen et al., 2014a). To determine the paired-pulse ratio (PPR), we generated a pair of stimuli at $50 \mathrm{~ms}$ intervals to evoke two EPSCs. The PPR was expressed as the ratio of the amplitude of the second synaptic response to the amplitude of the first synaptic response (Xie et al., 2017).

In some experiments, we recorded postsynaptic NMDAR currents elicited by puff application of $100 \mu \mathrm{M}$ NMDA directly onto the neuron using a positive pressure system (Toohey). The distance was $150 \mu \mathrm{m}$ between the tip of the puff pipette and the recorded neuron (S. R. Chen et al., 2014b). The internal solution used for recording electrodes contained the following (in mM): $110 \mathrm{Cs}_{2} \mathrm{SO}_{4}, 2 \mathrm{MgCl}_{2}, 0.5 \mathrm{CaCl}_{2}, 5 \mathrm{EGTA}$, 10 HEPES, $0.3 \mathrm{Na}$-GTP, $2 \mathrm{Mg}$-ATP, and 10 QX314 (pH 7.3; 280-300 mOsm). We replaced $\mathrm{MgCl}_{2}$ with $\mathrm{CaCl}_{2}$ in the extracellular solution to minimize the $\mathrm{Mg}^{2+}$ block of NMDARs at negative holding potentials. Recording signals were filtered at $1-2 \mathrm{kHz}$ and digitized at $10 \mathrm{kHz}$ using a MultiClamp 700B amplifier (Molecular Devices). We monitored cell capacitance, input resistance, and baseline holding current; the recording was discontinued if these parameters changed $>15 \%$.

TTX and AP5 were purchased from Hello Bio. NMDA was obtained from Sigma Millipore. All drugs were prepared in aCSF before recordings 
were obtained, and all drugs were delivered at their final concentrations via syringe pumps.

\section{Immunoblotting}

We used immunoblotting to quantify the $\alpha 2 \delta-1$ and GluN1 protein levels in the spinal cord and DRG. Spinal cord and DRG tissues were removed from mice anesthetized with $2 \%-3 \%$ isoflurane, dissected, and homogenized in ice-cold RIPA lysis buffer (Thermo Fisher Scientific) in the presence of a cocktail of protease and phosphatase inhibitors (Sigma Millipore). Samples were then incubated for $30 \mathrm{~min}$ on ice with shaking, and lysates were centrifuged at $13,000 \times g$ for $20 \mathrm{~min}$ at $4^{\circ} \mathrm{C}$. We loaded $40 \mu \mathrm{g}$ of total proteins from each sample to $4 \%-15 \%$ Tris-HCl SDSPAGE (Thermo Fisher Scientific) and transferred the samples onto PVDF membranes (Immobilon-P, Sigma Millipore). The membrane was treated with 5\% blotting-grade buffer in TBS with Tween 20 for $1 \mathrm{~h}$ at $25^{\circ} \mathrm{C}$ and then incubated with the following primary antibodies overnight at $4^{\circ} \mathrm{C}$ : mouse anti- $\alpha 2 \delta-1$ (\#sc-271697, 1:1000; Santa Cruz Biotechnology), rabbit anti-GluN1 (\#G-8913, 1:1000; Sigma Millipore), or rabbit anti-GAPDH (\#5174, 1:2000; Cell Signaling Technology). The specificity of primary antibodies has been confirmed in previous studies (J. Chen et al., 2018; Ma et al., 2018; Deng et al., 2019b). The membrane was washed three times with TBS with Tween 20 and then incubated with an HRP-conjugated secondary antibody: anti-rabbit IgG (\#111-036-003, 1:7500) or anti-mouse IgG (1:7500; both from Jackson ImmunoResearch Laboratories). The target protein bands were visualized with an ECL kit (Thermo Fisher Scientific), and protein band intensity was quantified using the Odyssey Fc Imager (LI-COR Biosciences) and normalized to the GADPH level on the same blot.

\section{Coimmunoprecipitation}

Coimmunoprecipitation was used to assess protein-protein interaction, as described previously (J. Chen et al., 2018; Ma et al., 2018). The dorsal spinal cord tissues were dissected and homogenized in ice-cold immunoprecipitation lysis buffer (Thermo Fisher Scientific) containing a cocktail of protease and phosphatase inhibitors. The protein lysate was incubated at $4^{\circ} \mathrm{C}$ overnight with Protein A/G beads (\#16-266; Sigma Millipore) prebound to rabbit anti-GluN1 antibody (\#G-8913, 1:1000; Sigma Millipore). Samples were washed three times with immunoprecipitation lysis buffer and extracted using $10 \%$ SDS. Mouse anti- $\alpha 2 \delta-1$ (\#sc-271697, 1:1000; Santa Cruz Biotechnology) and rabbit anti-GluN1 antibodies were used for immunoblotting. For the secondary antibody, we used anti-mouse IgG (1:7500; Jackson ImmunoResearch Laboratories) and True blot anti-rabbit IgG (\#18-8816-33, 1:7000; Rockland).

\section{Synaptosome preparation}

Synaptosomes were isolated from the dorsal spinal cord, as described previously (J. Chen et al., 2018; Y. Chen et al., 2019). The spinal cord tissues were pooled from 2 mice and homogenized using 10 volumes of ice-cold HEPES-buffered sucrose (0.32 M sucrose, $4 \mathrm{~mm}$ HEPES, and 1 mM EGTA, pH 7.4) containing the protease inhibitor cocktail (Sigma Millipore). The homogenate was centrifuged at $1000 \times \mathrm{g}$ for $10 \mathrm{~min}$ at $4^{\circ}$ $\mathrm{C}$ to remove the nuclei and large debris. The supernatant was then centrifuged at $12000 \times g$ for $20 \mathrm{~min}$ to obtain the crude synaptosomes. The synaptosomal pellets were incubated in RIPA lysis buffer with a protease inhibitor cocktail for $1 \mathrm{~h}$ on ice, then centrifuged at $13000 \times \mathrm{rpm}$ for $15 \mathrm{~min}$ at $4^{\circ} \mathrm{C}$ to obtain the synaptosomal fraction. The supernatant was then used for immunoblotting analysis.

\section{Behavioral assessment of nociception}

To quantify mechanical nociception, we performed the paw pressure test using a Randall Selitto analgesiometer (IITC Life Science), as described previously (S. R. Chen et al., 2014a). A steady increasing force was generated and applied to the hindpaw, and the device was immediately stopped when the animal withdrew the paw. Each trial was repeated two or three times at $2 \mathrm{~min}$ intervals, and the mean value of the force was used as the nociceptive threshold.

To detect tactile allodynia, we placed the mice individually in plastic chambers suspended on a mesh floor. After an acclimation period of $30 \mathrm{~min}$, calibrated von Frey filaments (Stoelting) were applied perpendicularly to the hindpaw with sufficient force to bend the filament for $6 \mathrm{~s}$, and a brisk paw withdrawal or flinching was considered a positive response. In brief, filaments were applied one by one to the plantar surface of the hindpaw. If no withdrawal response was observed, the filament with a greater force was applied; if there was a withdrawal response, the next less stiff filament was applied. Six consecutive responses from the first change in the response were used to calculate the withdrawal threshold (in grams) using the "updown" method (Chaplan et al., 1994).

To measure thermal nociception, we placed mice individually in an observation chamber on the glass surface maintained constantly at $30^{\circ} \mathrm{C}$ in a thermal testing apparatus (IITC Life Science). Mice were allowed to acclimate for $30 \mathrm{~min}$ before testing. As described previously (S. R. Chen et al., 2014a), a mobile radiant heat source located under the glass was targeted at the plantar surface of the hindpaw. The paw withdrawal latency was recorded by a timer, and the hindpaw was tested twice to obtain a mean withdrawal latency.

\section{Study design and statistical analysis}

Data are mean \pm SEM. We did not use any statistical methods to predetermine the sample sizes. However, our sample sizes were similar to those published previously (D. P. Li et al., 2002; S. R. Chen et al., 2014a, b; J. Chen et al., 2018). The investigators performing the behavioral and electrophysiological experiments were blinded to the treatments and genotypes. For electrophysiological experiments, 4-6 animals were used for each recording protocol, and only one neuron was recorded from each spinal cord slice. For postsynaptic NMDAR currents, we averaged the amplitude of currents elicited by three consecutive puff applications of NMDA. mEPSCs were analyzed offline using the MiniAnalysis program (Synaptosoft). Evoked EPSCs and puff NMDA currents were analyzed using Clampfit 10.0 software (Molecular Devices), and the amplitude of evoked EPSCs was quantified by averaging 6 consecutive EPSCs. The D'Agostino-Pearson normality test was used to assess the normality of data, and no test for outliers was conducted. Data from male and female WT mice were pooled because they showed similar changes to FK506 treatment. Two-tailed Student's $t$ tests were used to determine the differences between two groups, and one-way ANOVA followed by Tukey's post hoc test or repeated-measures ANOVA followed by the Dunnett's post hoc test was used to compare more than two groups. Two-way ANOVA followed by the Tukey's post hoc test was used to compare the behavioral data. All statistical analyses were performed using Prism software (version 7, GraphPad Software). $p$ values of $<0.05$ were considered statistically significant.

\section{Results}

\section{Treatment with FK506 increases the coupling of $\alpha 2 \delta$-1 and NMDARs in the spinal cord}

FK506 is the preferred drug for modern immunosuppression regimens (Tanabe, 2003; Snell et al., 2013). Peripheral nerve injury increases $\alpha 2 \delta-1$ expression in the DRG (Luo et al., 2001) and physical interaction between $\alpha 2 \delta-1$ and NMDARs in the spinal cord (J. Chen et al., 2018). We first quantified the $\alpha 2 \delta$-1 protein amount in both dorsal spinal cord and DRG tissues from mice treated with $3 \mathrm{mg} / \mathrm{kg}$ FK506 or vehicle for $7 \mathrm{~d}$. Immunoblotting showed that $\alpha 2 \delta-1$ protein levels in both the spinal cord and DRG were similar in FK506-treated and vehicle-treated mice $(n=8$ mice per group; Fig. $1 A, B)$.

We next conducted coimmunoprecipitation analyses to determine the interaction between $\alpha 2 \delta-1$ and GluN1, an obligatory subunit of NMDARs (Cull-Candy and Leszkiewicz, 2004). Treatment with FK506 significantly increased the prevalence of $\alpha 2 \delta$-1-GluN1 complexes in the dorsal spinal cord compared with that in the vehicle group ( $n=8$ mice per group, $p=0.0435$, $t_{(14)}=2.22$; Fig. $\left.1 C, D\right)$.

Treatment with FK506 promotes synaptic trafficking of $\alpha 2 \delta$ 1-NMDAR complexes in the spinal cord

$\alpha 2 \delta$-1 increases synaptic trafficking of NMDARs in the spinal cord after peripheral nerve injury (J. Chen et al., 2018). We thus 

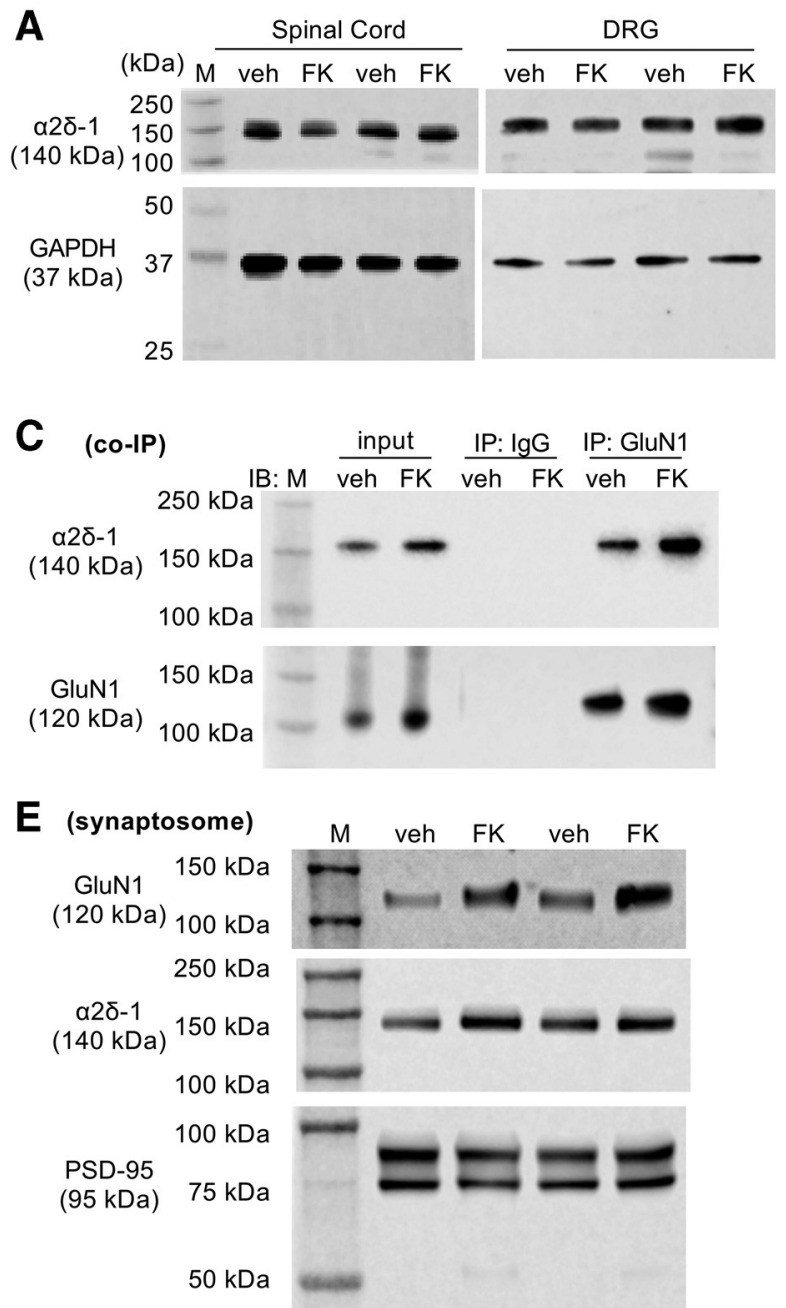
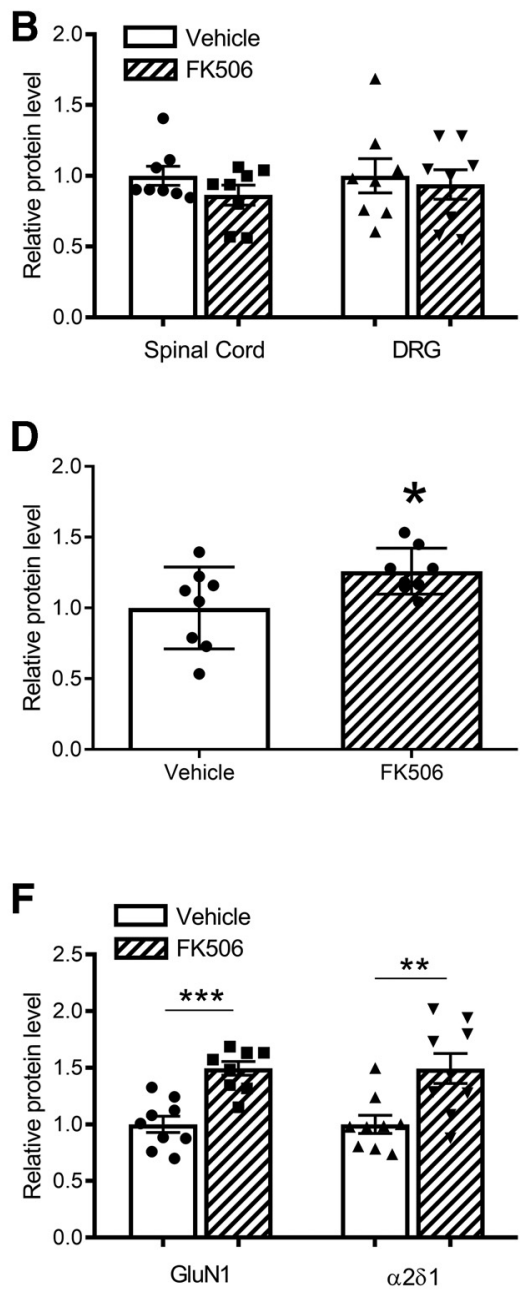

Figure 1. Treatment with FK506 increases $\alpha 2 \delta$-1-NMDAR interaction and synaptic trafficking in the spinal cord. $\boldsymbol{A}, \boldsymbol{B}$, Original blotting images ( $\boldsymbol{A}$, two pairs of samples) and quantification (B) of $\alpha 2 \delta$-1 protein levels in the DRG and dorsal spinal cord tissues of vehicle-treated (veh) and FK506-treated (FK) mice ( $n=8$ mice per group). C, D, Representative blotting image (C) and mean data (D) show the interaction between $\alpha 2 \delta-1$ and GluN1 in the tissue extracts of dorsal spinal cords from mice treated with vehicle and FK506 ( $n=8$ mice per group). Proteins were immunoprecipitated (IP) initially with a rabbit anti-GluN1 or anti-IgG antibody. Immunoblotting was then performed using mouse anti- $\alpha 2 \delta-1$ or rabbit anti-GluN1 antibodies. IgG and input (tissue lysates only, without immunoprecipitation) were used as negative and positive controls, respectively. $\boldsymbol{E}, \boldsymbol{F}$, Representative gel images ( $\boldsymbol{E}$, two pairs of samples) and quantification $(\boldsymbol{F})$ of the protein levels of GluN1, $\alpha 2 \delta$-1, and PSD-95 (a synaptic marker) in synaptosomes isolated from dorsal spinal cord tissues of vehicle-treated and FK506-treated mice ( $n=9$ mice per group). GAPDH or PSD-95 was used as the internal control for normalizing the protein level on the same gel. $M$, Molecular weight marker. $\boldsymbol{B}, \boldsymbol{D}, \boldsymbol{F}$, Values are normalized to expression levels in vehicle-treated mice in each group. Data are mean \pm SEM. ${ }^{*} p<0.05 ;{ }^{* *} p<0.01 ;{ }^{* * *} p<0.001$; compared with vehicle-treated group (two-tailed Student's $t$ test).

measured $\alpha 2 \delta-1$ and GluN1 protein amounts in isolated synaptosomes from the dorsal spinal cords of vehicle- and FK506treated mice. Both GluN1 ( $n=9$ mice per group; $p<0.0001$, $\left.t_{(16)}=5.27\right)$ and $\alpha 2 \delta-1 \quad(n=9$ mice per group; $p=0.0057$, $\left.t_{(16)}=3.19\right)$ protein levels in spinal synaptosomes were significantly higher in FK506-treated than in vehicle-treated mice (Fig. $1 E, F)$. These findings suggest that calcineurin inhibition enhances the synaptic trafficking of $\alpha 2 \delta$-1-bound NMDARs in the spinal cord.

Treatment with FK506 causes tonic activation of presynaptic NMDARs in the spinal dorsal horn via $\alpha \mathbf{2} \delta$-1

To identify changes in presynaptic NMDAR activity in spinal lamina II neurons, we recorded mEPSCs, which reflect quantal release of glutamate from presynaptic terminals (Sulzer and Pothos, 2000). The baseline frequency of mEPSCs in spinal lamina II neurons was significantly higher in FK506-treated than in vehicle-treated mice ( $n=11$ neurons in the FK506 group, $n=12$ neurons in the vehicle group, $5.45 \pm 0.57 \mathrm{~Hz}$ vs $2.73 \pm 0.38 \mathrm{~Hz}$; $\left.p=0.0086, F_{(11,132)}=3.43\right)$, whereas the amplitude of mEPSCs did not significantly differ between the two groups (Fig. 2A-D). We assessed NMDAR-mediated changes in mEPSC frequency using the specific NMDAR antagonist AP5. Bath application of $50 \mu \mathrm{M}$ AP5 for $6 \mathrm{~min}$ significantly reduced the frequency of mEPSCs $\left(p=0.0426, F_{(11,132)}=3.43\right)$ in lamina II neuron from FK506-treated, but not from vehicle-treated, mice (Fig. 2A-C). These data suggest that calcineurin inhibition induces tonic activation of presynaptic NMDARs in the spinal dorsal horn.

We next determined whether $\alpha 2 \delta$-1 plays a role in the increased presynaptic NMDAR activity in the spinal dorsal horn resulting from treatment with FK506. We treated spinal cord slices with $100 \mu \mathrm{M}$ gabapentin, an $\alpha 2 \delta$-1 inhibitory ligand (Marais et al., 2001; Fuller-Bicer et al., 2009), for $30 \mathrm{~min}$ before obtaining the recordings. Treatment with gabapentin normalized the baseline frequency in FK506-treated mice to the same level as in the vehicle group (Fig. $2 A-C$ ). Subsequent bath application of AP5 had no further effect on the frequency of mEPSCs of lamina II neuron in FK506-treated mice ( $n=13$ neurons; Fig. $2 A-C$ ). 
A

(WT+vehicle)

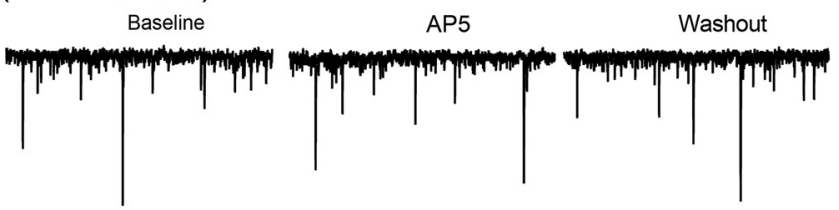

(WT+FK506)

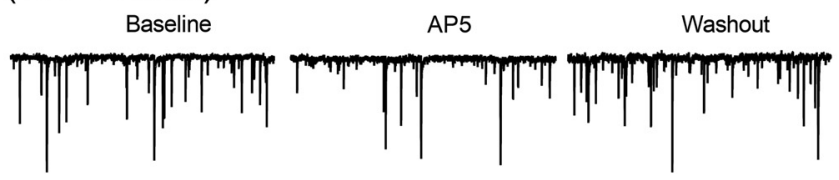

B

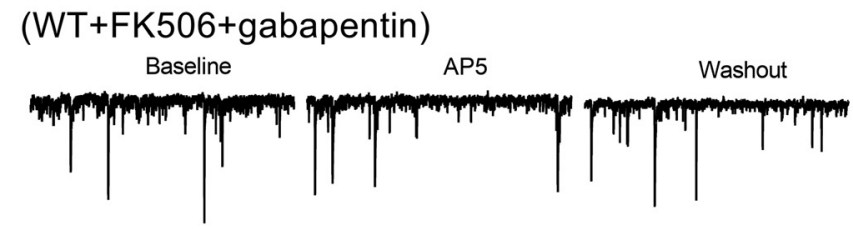

(Cacna2d1-KO+FK506)
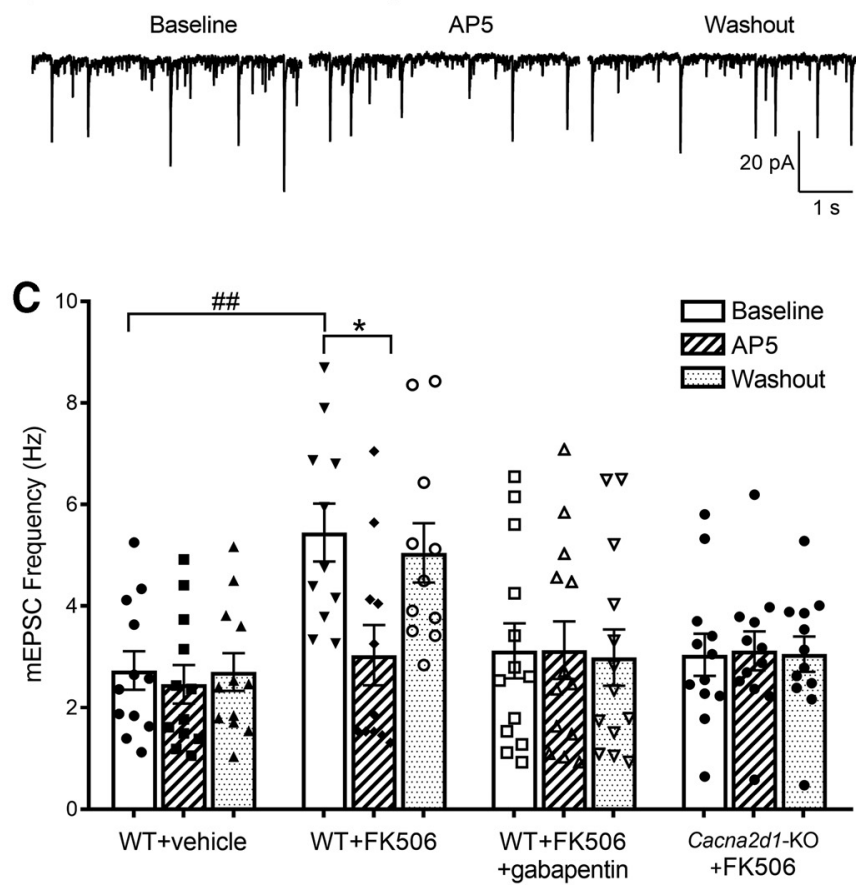
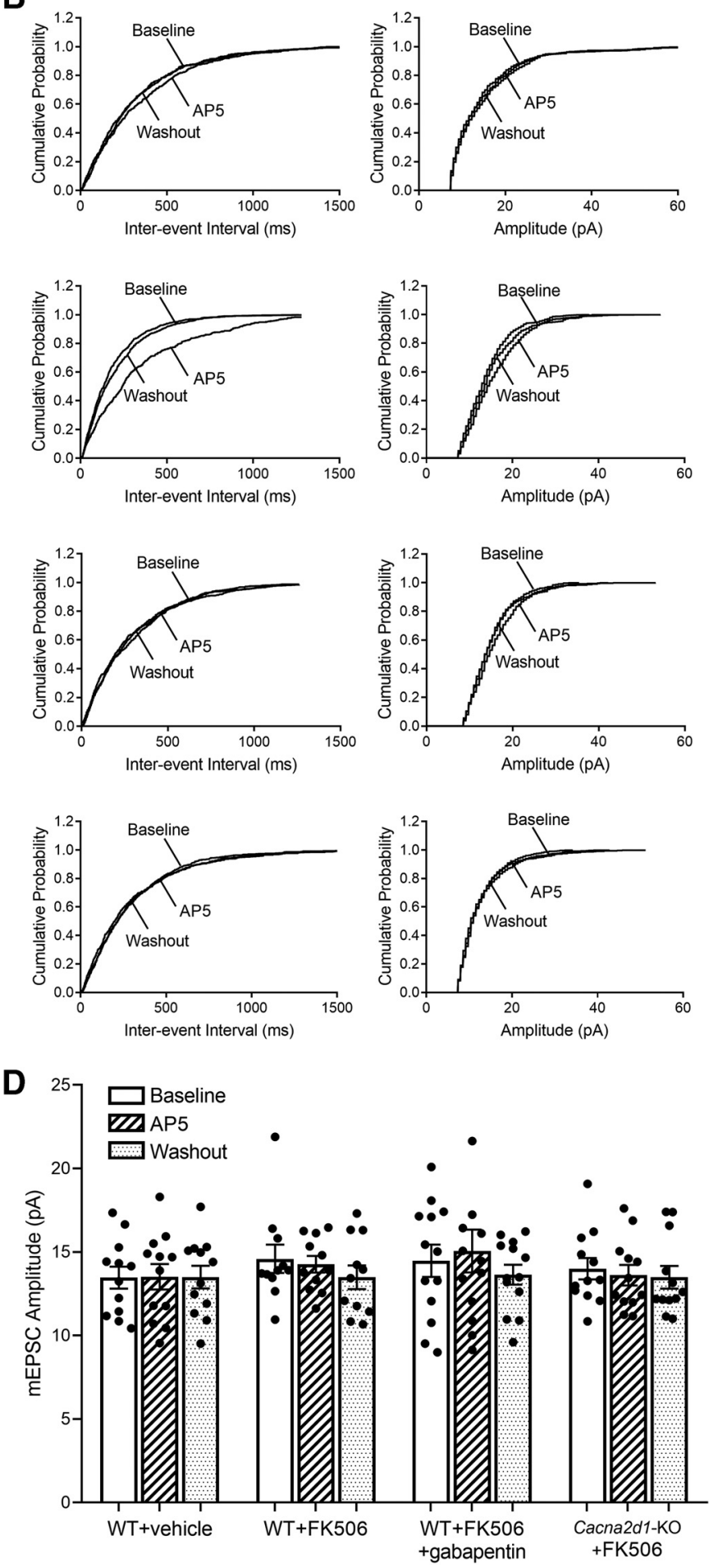

Figure 2. $\alpha 2 \delta$-1 is essential for FK506-induced activation of presynaptic NMDARs in the spinal dorsal horn. $\boldsymbol{A}, \boldsymbol{B}, 0$ riginal recording traces $(\boldsymbol{A})$ and cumulative probability plots $(\boldsymbol{B})$ show the effect of bath application of $50 \mu \mathrm{m}$ AP5 on mEPSCs of lamina II neurons from vehicle-treated mice, FK506-treated mice, FK506-treated mice from which spinal cord slices were incubated with $100 \mu \mathrm{m}$ gabapentin, and FK506-treated Cacna2d1-K0 mice. $\boldsymbol{C}, \boldsymbol{D}$, Summary data show the effect of AP5 on the frequency (C) and amplitude (D) of mEPSCS of lamina II neurons from vehicletreated mice ( $n=12$ neurons from 4 mice), FK506-treated mice ( $n=11$ neurons from 5 mice), FK506-treated mice from which spinal cord slices were incubated with gabapentin ( $n=13$ neurons from 6 mice), and FK506-treated Cacna2d1-K0 mice ( $n=12$ neurons from 4 mice). Data are mean \pm SEM. * $p<0.05$ compared with respective baseline (one-way ANOVA followed by Tukey's post hoc test). ${ }^{\#} p<0.01$ compared with baseline in the vehicle group (one-way ANOVA followed by Tukey's post hoc test).

Gabapentin and pregabalin bind to both $\alpha 2 \delta-1$ and $\alpha 2 \delta-2$ (Gee et al., 1996; Marais et al., 2001; Fuller-Bicer et al., 2009). To further validate the role of $\alpha 2 \delta$-1 in FK506-induced enhancement of presynaptic NMDAR activity, we recorded mEPSCs in dorsal horn neurons from FK506-treated Cacna2d1-KO mice. The frequency or amplitude of mEPSCs did not differ significantly between FK506-treated Cacna2d1-KO mice and vehicletreated WT mice ( $n=12$ neurons in each group; Fig. $2 A-D)$. In 
A
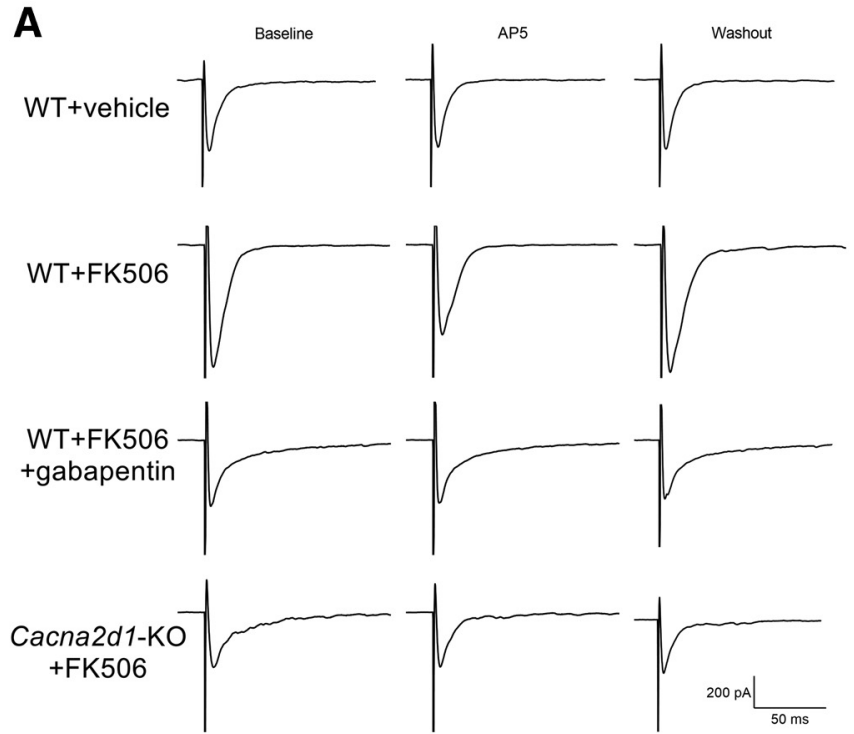

B

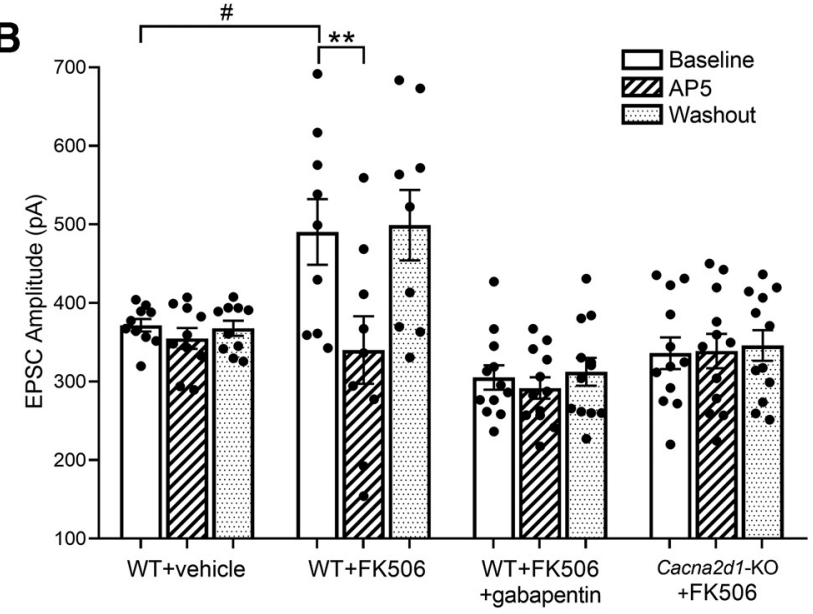

C
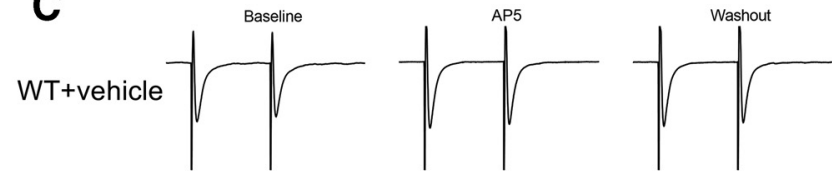

WT+FK506
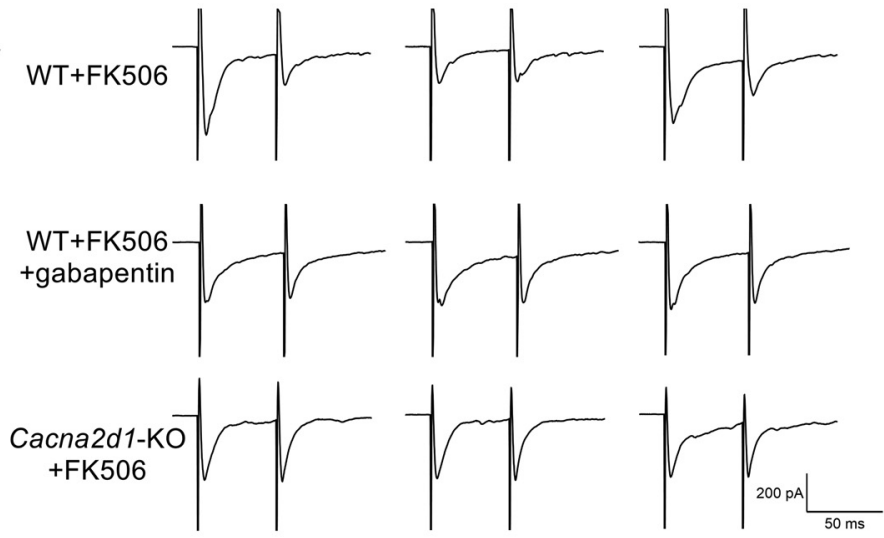

D

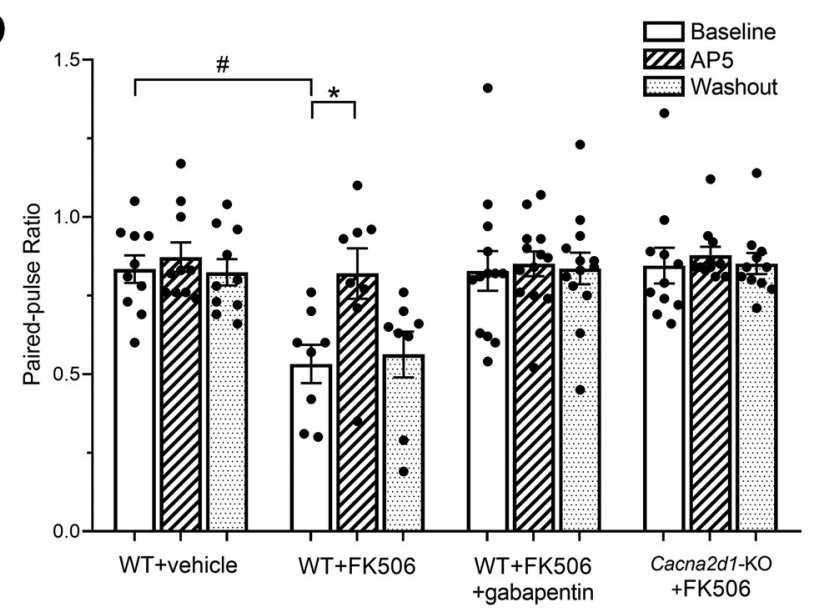

Figure 3. $\alpha 2 \delta$-1 mediates FK506-induced activation of NMDARs at primary afferent terminals in the spinal dorsal horn. $\boldsymbol{A}, \boldsymbol{B}$, Original recording traces $(\boldsymbol{A})$ and summary data $(\boldsymbol{B})$ show the effect of $50 \mu \mathrm{m}$ AP5 on the amplitude of evoked monosynaptic EPSCs of lamina II neurons from vehicle-treated mice ( $n=10$ neurons from 4 mice), FK506-treated mice ( $n=9$ neurons from 5 mice), FK506-treated mice from which spinal cord slices were incubated with $100 \mu \mathrm{m}$ gabapentin ( $n=12$ neurons from 6 mice), and FK506-treated Cacna2d1-K0 mice ( $n=12$ neurons from 4 mice). $\boldsymbol{C}, \boldsymbol{D}$, Representative recording traces $(\boldsymbol{C})$ and mean data $(\boldsymbol{D})$ show the effect of $50 \mu \mathrm{M}$ AP5 on the PPR of evoked EPSCs on lamina II neurons from vehicle-treated mice ( $n=10$ neurons from 4 mice), FK506-treated mice ( $n=8$ neurons from 5 mice), FK506-treated mice from which spinal cord slices were incubated with gabapentin ( $n=13$ neurons from 6 mice), and FK506treated Cacna2d1-KO mice ( $n=11$ neurons from 4 mice). Data are mean \pm SEM. ${ }^{*} p<0.05$; ${ }^{* *} p<0.01$; compared with respective baseline; ${ }^{\#} p<0.05$ compared with baseline in the vehicle group (one-way ANOVA followed by Tukey's post hoc test).

FK506-treated Cacna2d1-KO mice, bath application of AP5 did not alter the frequency or amplitude of mEPSCs of lamina II neurons (Fig. $2 A-C$ ). These findings indicate that $\alpha 2 \delta-1$ is required for calcineurin inhibitor-induced aberrant activation of presynaptic NMDARs in the spinal dorsal horn.

\section{$\alpha 2 \delta$-1 is essential for FK506-induced tonic activation of NMDARs at central terminals of primary afferents}

To specifically determine the role of NMDARs in synaptic glutamate release from central terminals of primary afferent nerves, we recorded EPSCs monosynaptically evoked from the dorsal root. The baseline amplitude of evoked EPSCs in lamina II neurons was significantly higher in FK506-treated than in vehicletreated mice ( $n=9$ neurons in the FK506 group, $n=10$ neurons in the vehicle group; $490.4 \pm 41.7 \mathrm{pA}$ vs $371.5 \pm 8.0 \mathrm{pA} ; p=0.0417$, $F_{(11,117)}=7.10$; Fig. $\left.3 A, B\right)$. Moreover, the PPR of evoked EPSCs was significantly lower in FK506-treated than in vehicle-treated mice ( $n=8$ neurons in the FK506 group, $n=10$ neurons in the vehicle group; $0.53 \pm 0.06$ vs $0.83 \pm 0.04, p=0.0127, F_{(11,114)}=4.09$; Fig. $3 C, D)$. Bath application of $50 \mu \mathrm{M}$ AP5 reversibly normalized the amplitude and PPR of evoked monosynaptic EPSCs in lamina II neurons from FK506-treated mice (Fig. 3A-D). However, AP5 had no effect on the amplitude or PPR of evoked EPSCs in lamina II neurons from WT mice treated with vehicle (Fig. 3A$D$ ). These data suggest that calcineurin inhibition causes tonic activation of presynaptic NMDARs at primary afferent central terminals.

Treatment with $100 \mu \mathrm{M}$ gabapentin for $30 \mathrm{~min}$ normalized the amplitude of evoked EPSCs $(n=12$ neurons, Fig. $3 A, B)$ and the PPR ( $n=13$ neurons; Fig. $3 C, D)$ in lamina II neurons from FK506-treated mice. Subsequent bath application of $50 \mu \mathrm{M}$ AP5 had no further effect on the amplitude or PPR of evoked EPSCs in these neurons (Fig. 3A-D).

In addition, the amplitude of evoked EPSCs and the PPR did not differ significantly between FK506-treated Cacna2d1-KO and vehicle-treated WT mice. Also, bath application of AP5 had 
A

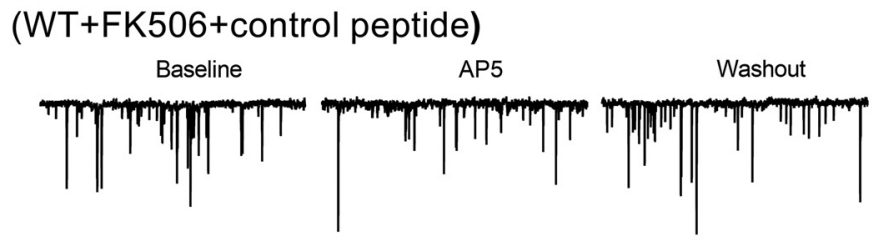

(WT+FK506+a2ס-1Tat peptide)
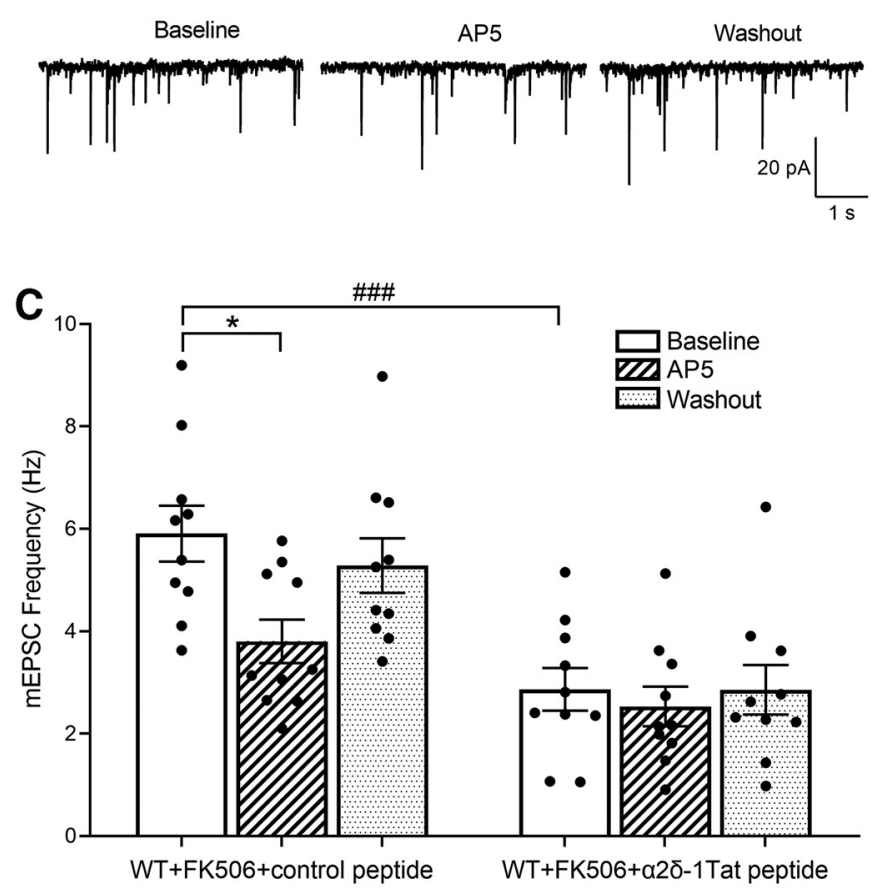

B
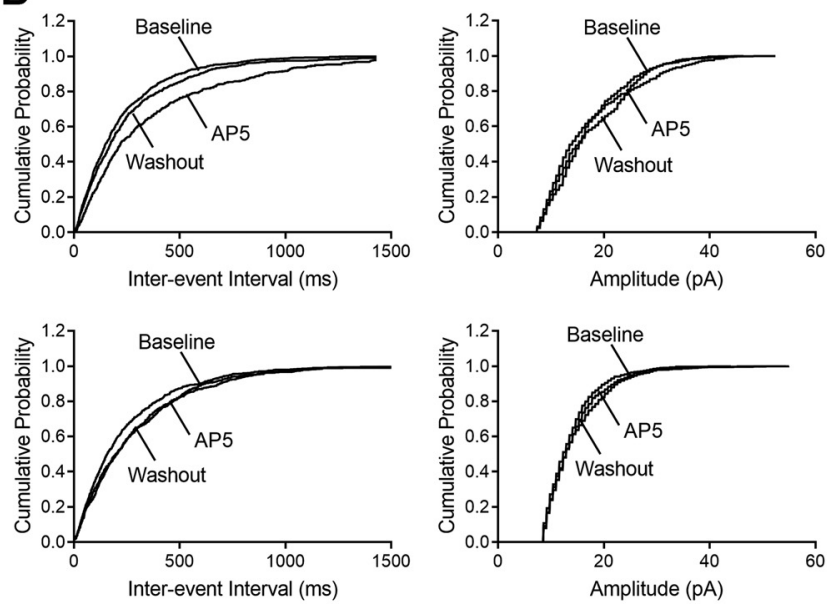

D

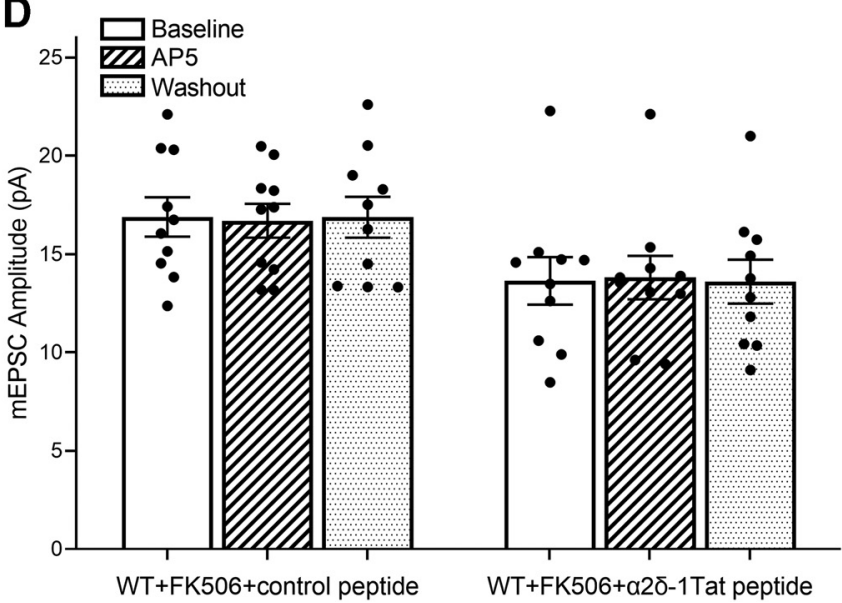

Figure 4. $\alpha 2 \delta$-1-bound NMDARs are involved in FK506-induced activation of presynaptic NMDARs in the spinal dorsal horn. $\boldsymbol{A}, \boldsymbol{B}$, Original recording traces $(\boldsymbol{A})$ and cumulative probability plots $(\boldsymbol{B})$ show the effect of bath application of $50 \mu \mathrm{m}$ AP5 on mEPSCs of lamina II neurons from FK506-treated WT mice in which spinal cord slices were incubated with $1 \mu \mathrm{m}$ control peptide or $1 \mu \mathrm{m} \alpha 2 \delta$-1Tat peptide. $\boldsymbol{C}, \boldsymbol{D}$, Summary data show the effect of AP5 on the frequency $(\boldsymbol{C})$ and amplitude $(\boldsymbol{D})$ of mEPSCs of lamina II neurons from FK506-treated WT mice in which spinal cord slices were incubated with $1 \mu \mathrm{m}$ control peptide ( $n=10$ neurons from 6 mice) or $1 \mu \mathrm{M} \alpha 2 \delta$-1Tat peptide ( $n=10$ neurons from 5 mice). Data are mean \pm SEM. ${ }^{*} p<0.05$ compared with respective baseline; \#\# $p<0.001$ compared with baseline in the control peptide group (one-way ANOVA followed by Tukey's post hoc test).

no effect on the amplitude ( $n=12$ neurons; Fig. $3 A, B)$ or the PPR ( $n=11$ neurons; Fig. $3 C, D)$ of evoked EPSCs in lamina II neurons from FK506-treated Cacna2d1-KO mice. These findings indicate that calcineurin inhibitor-induced tonic activation of NMDARs at central terminals of primary afferents critically depends on $\alpha 2 \delta-1$.

$\alpha 2 \delta$-1-bound NMDARs mediate FK506-induced increases in synaptic glutamate release to spinal dorsal horn neurons

The C-terminus of $\alpha 2 \delta-1$ is predominantly involved in its interaction with NMDARs, and a 30-amino acid peptide mimicking the C-terminal domain of $\alpha 2 \delta$-1 fused with Tat protein $(\alpha 2 \delta-1$ Tat peptide) uncouples the $\alpha 2 \delta$-1-NMDAR association (J. Chen et al., 2018; Luo et al., 2018). To determine the role of $\alpha 2 \delta$-1-bound NMDARs in FK506-induced tonic activation of presynaptic NMDARs, we treated the spinal cord slices from FK506-treated mice with $1 \mu \mathrm{m} \alpha 2 \delta$-1Tat peptide or Tat-fused scrambled control peptide for $30 \mathrm{~min}$ before obtaining recordings. $\alpha 2 \delta$-1Tat peptide incubation fully reversed the increased frequency of mEPSCs in spinal lamina II neurons from FK506-treated mice ( $n=10$ neurons; Fig. $4 A-C$ ). Also, subsequent bath application of $50 \mu \mathrm{M}$ AP5 had no effect on the mEPSC frequency in these neurons (Fig. 4AC). By contrast, treatment with the control peptide did not alter the baseline frequency of mEPSCs in lamina II neurons from FK506-treated mice. Furthermore, AP5 application still significantly reduced the frequency of mEPSCs in these neurons (from $5.91 \pm 0.55-3.80 \pm 0.42 \mathrm{~Hz} ; n=10$ neurons; $p=0.022, F_{(5,54)}=9.08$; Fig. $4 A-C)$.

In addition, incubation with $1 \mu \mathrm{M} \alpha 2 \delta$-1Tat peptide for 30 min completely normalized the baseline amplitude $(n=10$ neurons; Fig. $5 A, B)$ and PPR ( $n=9$ neurons; Fig. $5 C, D)$ of monosynaptic EPSCs evoked from the dorsal root in lamina II neurons from FK506-treated mice. Subsequent bath application of AP5 had no effect on the amplitude or PPR of evoked EPSCs in these neurons (Fig. 5A-D). However, in control peptide-treated spinal cord slices from FK506-treated mice, bath application of AP5 still significantly reduced the amplitude ( $n=12$ neurons; Fig. 5A,B) of monosynaptically evoked EPSCs and increased the PPR $(n=9$ neurons; Fig. $5 C, D$ ) in lamina II neurons. Together, these results strongly suggest that $\alpha 2 \delta$-1-bound NMDARs are essential for calcineurin inhibitor-induced tonic activation of presynaptic NMDARs at central terminals of primary afferent nerves. 
A
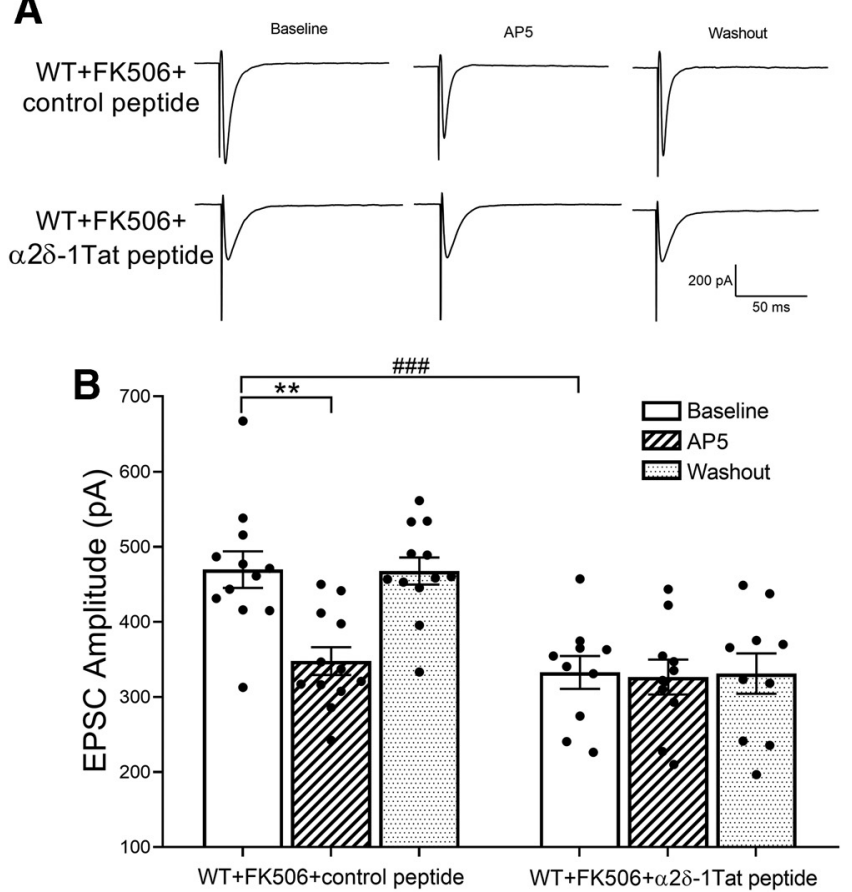
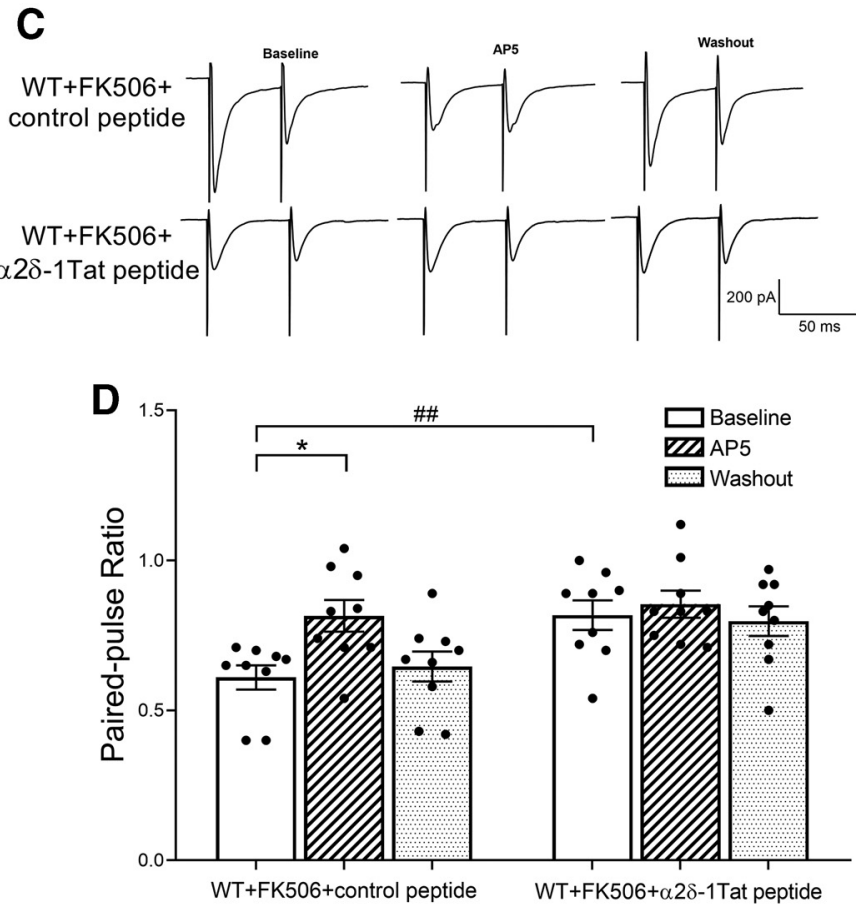

Figure 5. $\alpha 2 \delta$-1-bound NMDARs mediate FK506 treatment-induced activation of NMDARs at primary afferent terminals in the spinal dorsal horn. $\boldsymbol{A}, \boldsymbol{B}$, Representative current traces ( $\boldsymbol{A}$ ) and mean data $(\boldsymbol{B})$ show the effect of $50 \mu \mathrm{m} \mathrm{AP5}$ on the amplitude of monosynaptically evoked EPSCs of lamina II neurons from FK506-treated WT mice from which spinal cord slices were incubated with $1 \mu \mathrm{m}$ control peptide ( $n=12$ neurons from 6 mice) or $1 \mu \mathrm{m} \alpha 2 \delta$-1Tat peptide ( $n=10$ neurons from 5 mice). $\boldsymbol{C}$, D, Original recording traces $(\boldsymbol{C})$ and summary data $(\boldsymbol{D})$ show the effect of $50 \mu \mathrm{M}$ AP5 on the PPR of evoked EPSCS on lamina II neurons from FK506-treated WT mice from which spinal cord slices were incubated with $1 \mu \mathrm{m}$ control peptide $(n=9$ neurons from 6 mice) or $1 \mu \mathrm{M} \alpha 2 \delta$-1Tat peptide ( $n=9$ neurons from 5 mice). Data are mean \pm SEM. ${ }^{*} p<0.05$; ${ }^{* *} p<0.01$; compared with respective baseline. ${ }^{\#} p<0.01$; ${ }^{\# \#} p<0.001$; compared with baseline in the control peptide group (one-way ANOVA followed by Tukey's post hoc test).

\section{$\alpha 2 \delta$-1 mediates FK506-induced postsynaptic NMDAR hyperactivity in the spinal dorsal horn}

To determine postsynaptic NMDAR activity in the spinal dorsal horn altered by treatment with FK506, we recorded currents elicited by puff application of $100 \mu \mathrm{M}$ NMDA directly to spinal lamina II neurons. The amplitude of NMDAR currents was significantly higher in FK506-treated than in vehicle-treated mice $(163.4 \pm 20.8 \mathrm{pA}$ vs $88.6 \pm 9.8 \mathrm{pA}, n=11$ neurons per group; $p=0.0013, F_{(3,37)}=10.19$; Fig. $\left.6 A, B\right)$, suggesting that postsynaptic NMDAR activity of spinal dorsal horn neurons is enhanced by treatment with FK506.

Treatment with $100 \mu \mathrm{M}$ gabapentin for 30 min normalized the amplitude of puff NMDAR currents in lamina II neurons from FK506-treated mice ( $n=9$ neurons; Fig. $6 A, B$ ). Furthermore, in spinal cord slices from FK506-treated Cacna2d1-KO mice, the amplitude of puff NMDAR currents of lamina II neurons $(n=10$ neurons; Fig. $6 A, B$ ) was similar to that observed in vehicle-treated WT mice.

In addition, we determined whether $\alpha 2 \delta$-1-bound NMDARs play a role in FK506-induced postsynaptic NMDAR hyperactivity. We incubated spinal cord slices from FK506-treated mice with 1 $\mu \mathrm{M} \alpha 2 \delta$-1Tat peptide or $1 \mu \mathrm{m}$ control peptide for $30 \mathrm{~min}$ before obtaining recordings. Treatment with $\alpha 2 \delta$-1Tat peptide, but not the control peptide, significantly reduced the amplitude of puff NMDAR currents in lamina II neurons $(\alpha 2 \delta$-1Tat peptide, $93.5 \pm 11.6 \mathrm{pA}, n=10$ neurons; control peptide, $164.4 \pm 26.5 \mathrm{pA}$, $n=12$ neurons; $p=0.033, t_{(20)}=2.29$; Fig. $\left.6 C, D\right)$. Together, these data suggest that $\alpha 2 \delta-1$ is crucially involved in calcineurin inhibitor-induced postsynaptic NMDAR hyperactivity in the spinal dorsal horn. $\alpha \mathbf{2 \delta}$-1 is required for FK506-induced pain hypersensitivity Systemic administration of $3 \mathrm{mg} / \mathrm{kg}$ FK506 in WT mice for 7 consecutive days caused a gradual decrease in withdrawal thresholds in response to von Frey filaments, heat, and noxious pressure $(n=11$ mice; Fig. $7 A)$. The peak effect of FK506 was reached at $\sim 10 \mathrm{~d}$ after the start of treatment with FK506 and persisted for at least $10 \mathrm{~d}$ after the last injection of FK506. The tactile, heat, and pressure withdrawal thresholds returned to the pretreatment control level 14d after discontinuing treatment with FK506. Systemic treatment with vehicle had no effect on tactile, heat, or pressure withdrawal thresholds in WT mice (Y. Chen et al., 2019). Intraperitoneal injection of $60 \mathrm{mg} / \mathrm{kg}$ gabapentin significantly increased the withdrawal thresholds in response to tactile, heat, and pressure stimuli applied to the hindpaw of WT mice treated with FK506 ( $n=8$ mice; Fig. $8 A$ ). We did not observe any evident sign of sedation in mice after injecting gabapentin at $60 \mathrm{mg} / \mathrm{kg}$. The fall latency, measured using the rotarod performance test (Cai et al., 2013), did not differ significantly between vehicle- and gabapentin-treated WT mice $30 \mathrm{~min}$ after intraperitoneal injection (103.3 \pm 8.1 vs $100.1 \pm 5.2 \mathrm{~s}, n=8$ mice per group).

To further determine whether $\alpha 2 \delta$-1 is involved in the development of FK506-induced pain hypersensitivity, we subjected Cacna2d1-KO mice to systemic treatment with $3 \mathrm{mg} / \mathrm{kg}$ FK506 for $7 \mathrm{~d}$. The baseline withdrawal thresholds in response to von Frey filaments, heat, and noxious pressure did not differ significantly between WT and Cacna2d1-KO mice (Fig. 7A). However, the reduction in tactile, heat, and pressure withdrawal thresholds resulting from treatment with FK506 was markedly attenuated in Cacna2d1-KO mice ( $n=11$ mice, Fig. $7 A$ ) compared with WT 


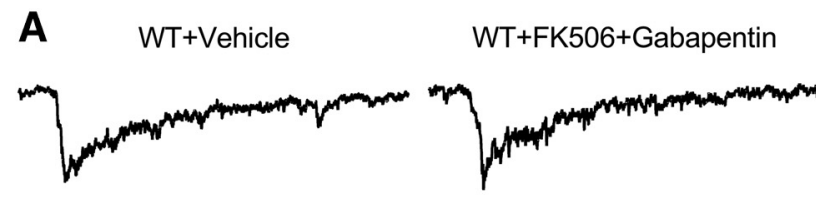

WT+FK506

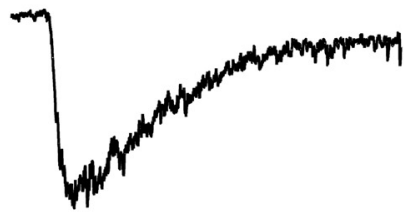

B

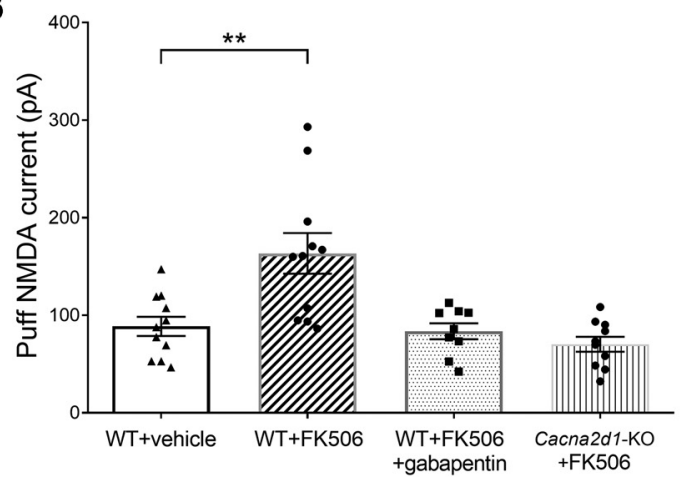

C WT+FK506+control peptide

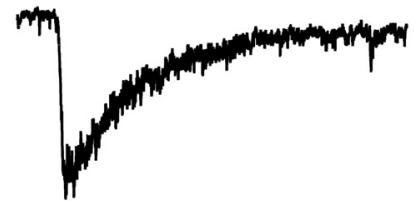

WT+FK506+a2ס-1Tat peptide

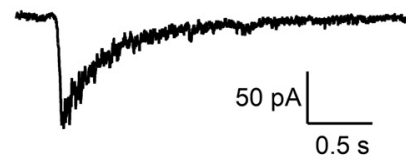

D

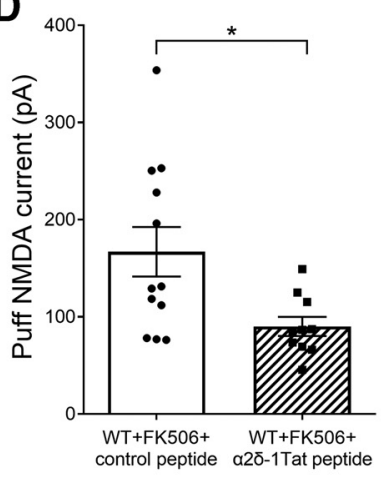

Figure 6. $\alpha 2 \delta$-1 is required for FK506-induced increases in postsynaptic NMDAR activity in the spinal dorsal horn. $\boldsymbol{A}, \boldsymbol{B}$, Representative current traces $(\boldsymbol{A})$ and mean data $(\boldsymbol{B})$ show NMDAR currents elicited by puff application of $100 \mu \mathrm{m}$ NMDA onto lamina II neurons from vehicle-treated WT mice ( $n=11$ neurons from 4 mice), FK506-treated WT mice ( $n=11$ neurons from 5 mice), FK506-treated Cacna2d1-K0 mice ( $n=10$ neurons from 4 mice), and FK506-treated mice from which spinal cord slices were incubated with $100 \mu \mathrm{m}$ gabapentin ( $n=9$ neurons from 4 mice). $\boldsymbol{C}, \boldsymbol{D}$, Original recording traces $(\boldsymbol{C})$ and group data $(\boldsymbol{D})$ show puff NMDA-elicited currents in lamina II neurons from FK506-treated mice from which spinal cord slices were incubated with $1 \mu \mathrm{m}$ control peptide ( $n=12$ neurons from 5 mice) or $1 \mu \mathrm{M} \alpha 2 \delta$-1Tat peptide ( $n=10$ neurons from 4 mice). Data are mean \pm SEM. ${ }^{*} p<0.05$; ${ }^{* *} p<0.01$; compared with the vehicle or control peptide group (one-way ANOVA followed by Tukey's post hoc test in $\boldsymbol{B}$; two-tailed Student's $t$ test in $\boldsymbol{D}$ ).

mice. Gabapentin had no effect on tactile, heat, or pressure withdrawal thresholds in Cacna2d1-KO mice treated with FK506 $(n=8$ mice, Fig. $8 A)$.

\section{$\alpha 2 \delta$-1-bound NMDARs at the spinal cord level mediate} FK506-induced pain hypersensitivity

Next, to determine whether FK506-induced mechanical and thermal hypersensitivity is mediated by $\alpha 2 \delta$-1-bound NMDARs at the spinal cord level, we intrathecally injected $1 \mu \mathrm{g}$ of $\alpha 2 \delta$ 1Tat peptide or $1 \mu \mathrm{g}$ control peptide in WT mice 3-5 $\mathrm{d}$ after the last FK506 injection. $\alpha 2 \delta$-1Tat peptide, but not control peptide, significantly attenuated the reduction in tactile, heat, and pressure withdrawal thresholds caused by FK506 ( $n=10$ mice; Fig. $8 B)$. Intrathecal injection of $1 \mu \mathrm{g} \alpha 2 \delta$-1Tat peptide had no effect on the paw withdrawal thresholds in Cacna2d1-KO mice treated with FK506 ( $n=10$ mice; Fig. $8 B$ ). These results indicate that $\alpha 2 \delta$-1-bound NMDARs at the spinal cord level play a major role in calcineurin inhibitor-induced pain hypersensitivity.

NMDARs in primary sensory neurons are involved in FK506-induced pain hypersensitivity

Blocking NMDARs at the spinal cord level can rapidly reverse pain hypersensitivity induced by FK506 treatment in rats (S. R. Chen et al., 2014a). In addition, our electrophysiological data suggest that presynaptic NMDARs play a major role in the augmented nociceptive input from primary afferent nerves to spinal dorsal horn neurons in FK506-treated mice. We thus used Grin1-cKO (Advillin ${ }^{\mathrm{Cre} /+}:$ :Grin1 $\left.{ }^{\text {flox/flox }}\right)$ mice in which functional NMDARs are inactivated in primary sensory neurons to determine whether NMDARs in primary sensory neurons are involved in the development of FK506-induced mechanical and thermal hypersensitivity. The GluN1 protein level in the DRG was diminished in Grin1-cKO mice compared with WT mice $\left(n=11\right.$ mice per group; $p<0.0001, t_{(20)}=6.72$; Fig. $\left.7 B, C\right)$. Also, the GluN1 protein level in the dorsal spinal cord was significantly lower in Grin1-cKO than in WT mice ( $n=11$ mice per group; $p=0.0008, t_{(20)}=3.96$; Fig. $\left.7 B, C\right)$, suggesting that some GluN1 proteins in the spinal dorsal horn were synthesized by DRG neurons and transported to the primary afferent central terminals (H. Liu et al., 1994).

There was no significant difference in the baseline mechanical and thermal withdrawal thresholds between Grin1-cKO and WT mice (Fig. 7A). In Grin1-cKO mice, treatment with vehicle had no significant effect on withdrawal thresholds in response to von Frey filaments, heat, and noxious pressure ( $n=10$ mice; Fig. $7 A$ ). The reduction in tactile, heat, and pressure withdrawal thresholds was significantly attenuated in Grin1-cKO mice treated with FK506 ( $n=10$ mice; Fig. 7A) compared with FK506-treated WT mice. These behavioral data indicate that presynaptic NMDARs originating from primary sensory neurons contribute to calcineurin inhibitor-induced pain hypersensitivity. 

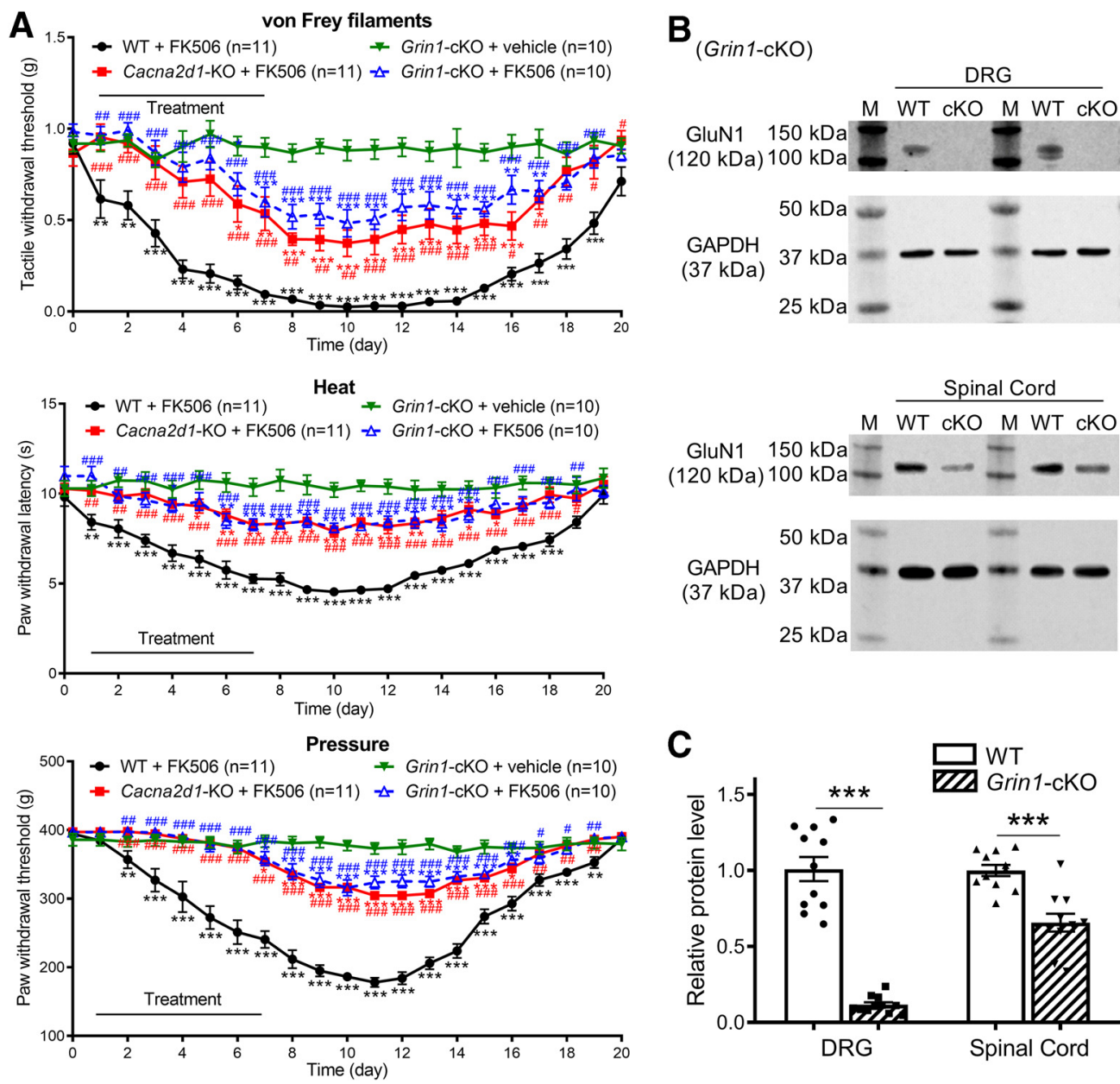

Figure 7. $\alpha 2 \delta-1$ and NMDARs expressed in primary sensory neurons contribute to FK506-induced pain hypersensitivity. $\boldsymbol{A}$, Time course of changes in paw withdrawal thresholds tested with von Frey filaments, a heat stimulus, and a noxious pressure stimulus in WT and Cacna2d1-K0 mice treated with FK506 ( $n=11$ mice per group) and in Grin1-cK0 mice treated with vehicle or FK506 ( $n=10$ mice per group) for $7 \mathrm{~d}$. Solid bar represents daily drug injections. Data are mean \pm SEM. ${ }^{*} p<0.05 ;{ }^{* *} p<0.01 ;{ }^{* * *} p<0.001$; compared with respective baselines before treatment with FK506 (time 0). ${ }^{\#} p<0.05 ;{ }^{\# \#} p<0.01$; \#\#\# $p<0.001$; compared with the WT+FK506 group at the same time point (two-way ANOVA followed by Dunnett's or Tukey's post hoc test). $\boldsymbol{B}, \boldsymbol{C}$, Representative blotting images $(\boldsymbol{B})$ and mean data $(\boldsymbol{C})$ show the GluN1 protein levels in the DRG and dorsal spinal cord tissues from WT and Grin1-cK0 mice $(n=11$ mice per group). M, Molecular weight marker. Data are mean \pm SEM. ${ }^{* * *} p<0.001$ compared with the WT group (two-tailed Student's $t$ test).

\section{Discussion}

Our study used complementary biochemical, electrophysiological, and behavioral approaches and revealed that $\alpha 2 \delta-1$ plays a prominent role in calcineurin inhibitor-induced aberrant activation of NMDARs, at presynaptic and postsynaptic sites, in the spinal dorsal horn. In a mouse model of CIPS, we found that treatment with FK506 potentiated NMDAR activity in the spinal dorsal horn, which is consistent with the findings in rats treated with FK506 (S. R. Chen et al., 2014a). By using gabapentin as an $\alpha 2 \delta$-1 inhibitory ligand as well as Cacna $2 d 1-\mathrm{KO}$ mice and the $\alpha 2 \delta$-1Tat blocking peptide, our study provided substantial evidence for the involvement of $\alpha 2 \delta-1$ in calcineurin inhibitorinduced synaptic NMDAR plasticity in the spinal dorsal horn.

It is interesting to note that CIPS shares strikingly similar mechanisms with neuropathic pain caused by traumatic nerve injury (S. R. Chen et al., 2014b; J. Chen et al., 2018). This is because $\alpha 2 \delta$-1-bound NMDARs are required for the increased activity of presynaptic and postsynaptic NMDARs in both painful conditions. Consistent with our findings in animal models, patients with CIPS manifest certain neuropathic pain symptoms, such as tactile allodynia (Grotz et al., 2001; Fujii et al., 2006; Noda et al., 2008; Tasoglu et al., 2016; Wei et al., 2018).
Furthermore, calcineurin is downregulated in the spinal dorsal horn after sciatic nerve injury (Miletic et al., 2015), and intrathecal injection of calcineurin reduces nerve injury-induced pain hypersensitivity (Miletic et al., 2013). We showed that prolonged calcineurin inhibition with FK506 increased the $\alpha 2 \delta-1-$ NMDAR association and synaptic expression of $\alpha 2 \delta$-1-bound NMDARs, which explains the increased NMDAR activity at the spinal cord level. Therefore, our findings support the notion that endogenous calcineurin functions as an intrinsic negative regulator of nociceptive transmission via the control of $\alpha 2 \delta-1-$ NMDAR interaction and synaptic trafficking.

An important finding of our study is that $\alpha 2 \delta-1$ and $\alpha 2 \delta-1-$ bound NMDARs mediate calcineurin inhibitor-induced pain hypersensitivity. This conclusion is supported by our results showing that treatment with gabapentin or $\alpha 2 \delta$-1Tat peptide attenuated FK506-induced mechanical and thermal hypersensitivity. Also, FK506-induced hypersensitivity was much lower in mice lacking $\alpha 2 \delta-1$ than in WT mice. Calcineurin inhibition prolongs the NMDAR channel opening and enhances synaptic NMDAR activity in hippocampal neurons (Lieberman and Mody, 1994; Tong et al., 1995). The causal relationship between NMDAR phosphorylation and the $\alpha 2 \delta$-1-NMDAR interaction 

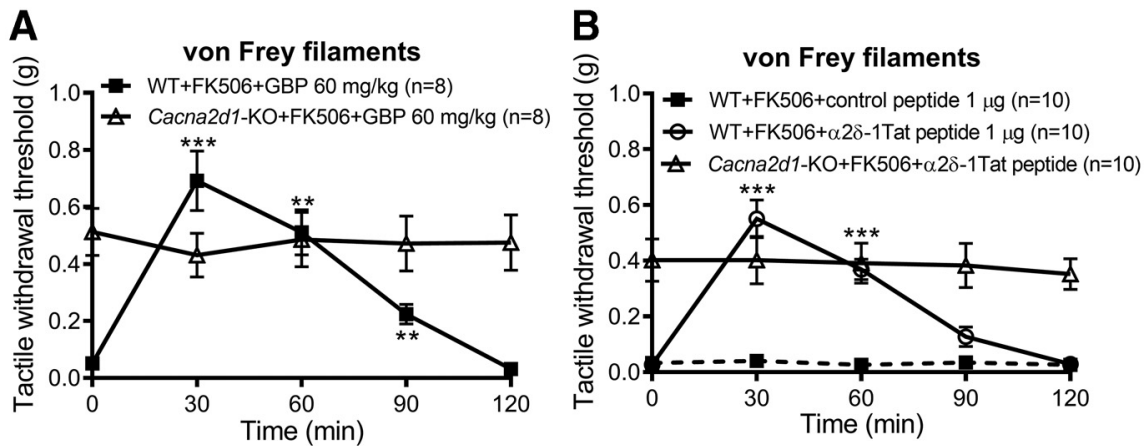

Heat
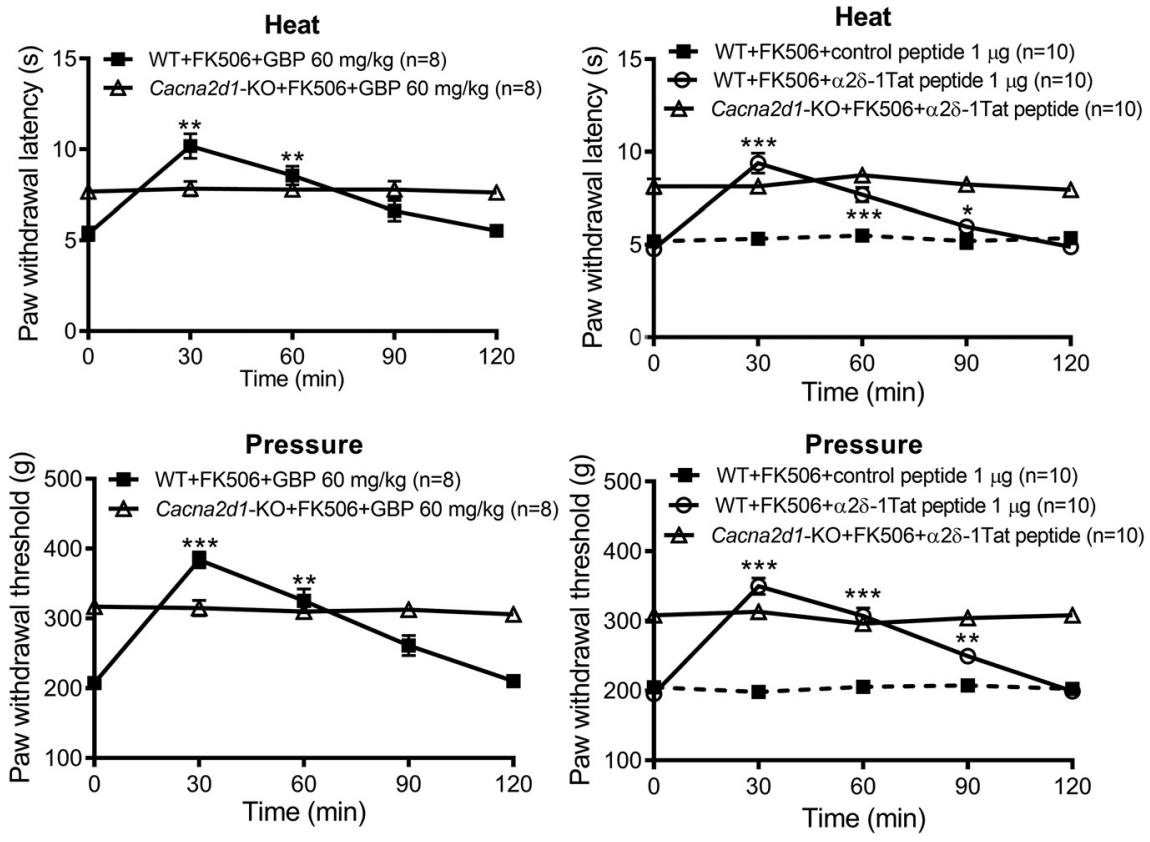

Figure 8. $\alpha 2 \delta-1$ inhibition or K0 and blocking $\alpha 2 \delta$-1-NMDAR interaction reverse FK506-induced pain hypersensitivity in mice. $A$, Time course of the effect of intraperitoneal injection with $60 \mathrm{mg} / \mathrm{kg}$ gabapentin (GBP) on paw withdrawal thresholds tested with von Frey filaments, a heat stimulus, and a noxious pressure stimulus in FK506-treated WT mice and Cacna2d1-K0 mice ( $n=8$ mice per group). $\boldsymbol{B}$, Time course of the effects of intrathecal injection with $1 \mu \mathrm{g}$ control peptide or $1 \mu \mathrm{g} \alpha 2 \delta$-1Tat peptide on paw withdrawal thresholds in response to von Frey filaments, a heat stimulus, and a noxious pressure stimulus in FK506-treated WT mice and FK506-treated Cacna2d1-K0 mice ( $n=10$ mice per group). Data are mean \pm SEM. ${ }^{*} p<0.05 ;{ }^{* *} p<0.01$; ${ }^{* * *} p<0.001$; compared with the baseline before drug injection (time 0 ; repeated-measures ANOVA followed by Dunnett's post hoc test).

remains unknown. Because calcineurin is a protein phosphatase, its inhibition could enhance the phosphorylation of NMDAR subunits (Krupp et al., 2002) or NMDAR-interacting proteins, such as calmodulin (Rycroft and Gibb, 2004). Also, reducing NMDAR phosphorylation by inhibiting casein kinase-2 activity abrogates the increased spinal cord NMDAR activity and pain hypersensitivity in FK506-treated rats (Hu et al., 2014). Phosphorylation can result in protein conformational changes and modulate the nature and strength of protein-protein interactions, thereby regulating the binding energy of the protein complex and coordinating different signaling pathways (Nishi et al., 2011; Betts et al., 2017). Thus, increasing NMDAR phosphorylation via calcineurin inhibition may change proteins' physicochemical conformation to promote the interaction between $\alpha 2 \delta-1$ and NMDARs.

Another salient finding of our study is that deleting GluN1 from DRG neurons significantly attenuated pain hypersensitivity caused by FK506. Presynaptic NMDARs can powerfully shape synaptic transmission and plasticity in the CNS (McGuinness et al., 2010; Park et al., 2014; Ma et al., 2018; J. J. Zhou et al., 2018).
Although NMDARs are present in primary sensory neurons and their central terminals (H. Liu et al., 1994), presynaptic NMDARs in the spinal dorsal horn are latent under normal conditions. We found that baseline nociceptive thresholds were similar in WT and Grin1-cKO mice, which is consistent with previous studies showing that intrathecal injection of NMDAR antagonists has no effect on nociception in normal animals (Yamamoto and Yaksh, 1992; H. Y. Zhou et al., 2012; S. R. Chen et al., 2014a; L. Li et al., 2016; Xie et al., 2016). Also, cKO of Grin1 in DRG neurons using $\mathrm{Prph}^{\mathrm{Cre} /+}$ mice removes $\sim 75 \%$ of GluN1 expression in the DRG but has no effect on the baseline nociception (McRoberts et al., 2011). Nevertheless, presynaptic NMDARs become tonically activated in opioidinduced hyperalgesia and neuropathic pain conditions (Zhao et al., 2012; Yan et al., 2013; S. R. Chen et al., 2014c; J. Chen et al., 2018; Y. Chen et al., 2019), leading to increased glutamatergic input to spinal dorsal horn neurons. Remarkably, we found that the degree of reduction in FK506induced pain hypersensitivity was similar in Grin1-cKO and Cacna2d1$\mathrm{KO}$ mice. This finding suggests that presynaptic $\alpha 2 \delta$-1-bound NMDARs at primary afferent central terminals contribute importantly to the development of CIPS.

Our study demonstrates that treatment with FK506 led to a large increase in postsynaptic NMDAR activity of spinal dorsal horn neurons, an increase that also required $\alpha 2 \delta-1$. Under normal conditions, NMDARs are minimally open because of the $\mathrm{Mg}^{2+}$ block (Kampa et al., 2004). However, the FK506-induced increase in glutamate release from primary afferents to spinal dorsal horn neurons can depolarize postsynaptic neurons, leading to $\mathrm{Mg}^{2+}$ block removal and postsynaptic NMDAR activation. Thus, postsynaptic NMDARs act in concert with activated presynaptic NMDARs to potentiate nociceptive transmission in CIPS. Activated postsynaptic NMDARs can increase intracellular $\mathrm{Ca}^{2+}$, resulting in calpain-mediated $\mathrm{K}^{+}-\mathrm{Cl}^{-}$cotransporter-2 cleavage and impairment of normal synaptic inhibition by GABA and glycine (H. Y. Zhou et al., 2012). Impaired synaptic inhibition in the spinal dorsal horn plays a key role in the development of neuropathic pain (Coull et al., 2003). In our study, FK506-induced pain hypersensitivity was not abolished in Grin1-cKO or Cacna2d1-KO mice. Other signaling mechanisms are also likely involved in CIPS due to increasing phosphorylation of other proteins by calcineurin inhibitors. For example, calcineurin inhibition potentiates phosphorylation of Kv2.1 channels (Park et al., 2006), which could increase neuronal excitability. Also, reduced calcineurin activity may affect GluA1 
phosphorylation and synaptic trafficking of $\mathrm{Ca}^{2+}$-permeable AMPA receptors (Kim and Ziff, 2014). Calcineurin inhibitors can also increase nociceptive transmission by augmenting the activity of voltage-activated $\mathrm{Ca}^{2+}$ channels in DRG neurons ( $\mathrm{Wu}$ et al., 2005, 2006). In addition, calcineurin may regulate TRPV1 channels and tandem pore domain $\mathrm{K}^{+}$channels (Mohapatra and Nau, 2005; Czirjak and Enyedi, 2006), although there is no direct evidence to link these channels to the pathophysiology of CIPS.

In conclusion, our study reveals that $\alpha 2 \delta$-1-bound NMDARs at the spinal cord level play a major role in the development of CIPS. Our findings advance the mechanistic understanding of the critical role of endogenous calcineurin in regulating nociceptive transmission and suggest a new, mechanism-based strategy for treating CIPS. Because general NMDAR antagonists, such as ketamine, are associated with serious adverse effects, targeting $\alpha 2 \delta-1-$ bound NMDARs with gabapentinoids and drugs that disrupt $\alpha 2 \delta$-1-NMDAR complexes could be a rational treatment for CIPS.

\section{References}

Betts MJ, Wichmann O, Utz M, Andre T, Petsalaki E, Minguez P, Parca L, Roth FP, Gavin AC, Bork P, Russell RB (2017) Systematic identification of phosphorylation-mediated protein interaction switches. PLoS Comput Biol 13:e1005462.

Cai YQ, Chen SR, Pan HL (2013) Upregulation of nuclear factor of activated $\mathrm{T}$ cells by nerve injury contributes to development of neuropathic pain. J Pharmacol Exp Ther 345:161-168.

Chaplan SR, Bach FW, Pogrel JW, Chung JM, Yaksh TL (1994) Quantitative assessment of tactile allodynia in the rat paw. J Neurosci Methods 53:55-63.

Chen J, Li L, Chen SR, Chen H, Xie JD, Sirrieh RE, MacLean DM, Zhang Y, Zhou MH, Jayaraman V, Pan HL (2018) The alpha2delta-1-NMDA receptor complex is critically involved in neuropathic pain development and gabapentin therapeutic actions. Cell Rep 22:2307-2321.

Chen SR, Zhou HY, Byun HS, Pan HL (2013) Nerve injury increases GluA2lacking AMPA receptor prevalence in spinal cords: functional significance and signaling mechanisms. J Pharmacol Exp Ther 347:765-772.

Chen SR, Hu YM, Chen H, Pan HL (2014a) Calcineurin inhibitor induces pain hypersensitivity by potentiating pre- and postsynaptic NMDA receptor activity in spinal cords. J Physiol 592:215-227.

Chen SR, Zhou HY, Byun HS, Chen H, Pan HL (2014b) Casein kinase II regulates N-methyl-D-aspartate receptor activity in spinal cords and pain hypersensitivity induced by nerve injury. J Pharmacol Exp Ther 350:301312.

Chen SR, Zhu L, Chen H, Wen L, Laumet G, Pan HL (2014c) Increased spinal cord $\mathrm{Na}(+)-\mathrm{K}(+)-2 \mathrm{Cl}(-)$ cotransporter-1 (NKCC1) activity contributes to impairment of synaptic inhibition in paclitaxel-induced neuropathic pain. J Biol Chem 289:31111-31120.

Chen Y, Chen SR, Chen H, Zhang J, Pan HL (2019) Increased alpha2delta-1NMDA receptor coupling potentiates glutamatergic input to spinal dorsal horn neurons in chemotherapy-induced neuropathic pain. J Neurochem 148:252-274.

Cole RL, Lechner SM, Williams ME, Prodanovich P, Bleicher L, Varney MA, Gu G (2005) Differential distribution of voltage-gated calcium channel alpha-2 delta (alpha2delta) subunit mRNA-containing cells in the rat central nervous system and the dorsal root ganglia. J Comp Neurol 491:246-269.

Coull JA, Boudreau D, Bachand K, Prescott SA, Nault F, Sik A, De Koninck P, De Koninck Y (2003) Trans-synaptic shift in anion gradient in spinal lamina I neurons as a mechanism of neuropathic pain. Nature 424:938942.

Cull-Candy SG, Leszkiewicz DN (2004) Role of distinct NMDA receptor subtypes at central synapses. Sci STKE 2004:re16.

Czirjak G, Enyedi P (2006) Targeting of calcineurin to an NFAT-like docking site is required for the calcium-dependent activation of the background $\mathrm{K}^{+}$channel. J Biol Chem 281:14677-14682.

da Silva S, Hasegawa H, Scott A, Zhou X, Wagner AK, Han BX, Wang F (2011) Proper formation of whisker barrelettes requires periphery- derived Smad4-dependent TGF-beta signaling. Proc Natl Acad Sci USA 108:3395-3400.

Deng M, Chen SR, Chen H, Pan HL (2019a) alpha2delta-1-bound N-methyl$\mathrm{D}$-aspartate receptors mediate morphine-induced hyperalgesia and analgesic tolerance by potentiating glutamatergic input in rodents. Anesthesiology 130:804-819.

Deng M, Chen SR, Chen H, Luo Y, Dong Y, Pan HL (2019b) Mitogenactivated protein kinase signaling mediates opioid-induced presynaptic NMDA receptor activation and analgesic tolerance. J Neurochem 148:275-290.

Denton MD, Magee CC, Sayegh MH (1999) Immunosuppressive strategies in transplantation. Lancet 353:1083-1091.

Fujii N, Ikeda K, Koyama M, Aoyama K, Masunari T, Kondo E, Matsuzaki T, Mizobuchi S, Hiraki A, Teshima T, Shinagawa K, Ishimaru F, Tanimoto M (2006) Calcineurin inhibitor-induced irreversible neuropathic pain after allogeneic hematopoietic stem cell transplantation. Int J Hematol 83:459-461.

Fuller-Bicer GA, Varadi G, Koch SE, Ishii M, Bodi I, Kadeer N, Muth JN, Mikala G, Petrashevskaya NN, Jordan MA, Zhang SP, Qin N, Flores CM, Isaacsohn I, Varadi M, Mori Y, Jones WK, Schwartz A (2009) Targeted disruption of the voltage-dependent calcium channel alpha2/delta-1-subunit. Am J Physiol Heart Circ Physiol 297:H117-H124.

Gee NS, Brown JP, Dissanayake VU, Offord J, Thurlow R, Woodruff GN (1996) The novel anticonvulsant drug, gabapentin (Neurontin), binds to the alpha2delta subunit of a calcium channel. J Biol Chem 271:57685776.

Grotz WH, Breitenfeldt MK, Braune SW, Allmann KH, Krause TM, Rump JA, Schollmeyer PJ (2001) Calcineurin-inhibitor induced pain syndrome (CIPS): a severe disabling complication after organ transplantation. Transplant Int 14:16-23.

Hu YM, Chen SR, Chen H, Pan HL (2014) Casein kinase II inhibition reverses pain hypersensitivity and potentiated spinal N-methyl-D-aspartate receptor activity caused by calcineurin inhibitor. J Pharmacol Exp Ther 349:239-247.

Huang Y, Chen SR, Chen H, Pan HL (2019) Endogenous transient receptor potential ankyrin 1 and vanilloid 1 activity potentiates glutamatergic input to spinal lamina I neurons in inflammatory pain. J Neurochem 149:381-398.

Isobe M, Suzuki J, Yamazaki S, Yazaki Y, Horie S, Okubo Y, Maemura K, Yazaki Y, Sekiguchi M (1997) Regulation by differential development of Th1 and Th2 cells in peripheral tolerance to cardiac allograft induced by blocking ICAM-1/LFA-1 adhesion. Circulation 96:2247-2253.

Kakihana K, Ohashi K, Murata Y, Tsubokura M, Kobayashi T, Yamashita T, Sakamaki H, Akiyama H (2012) Clinical features of calcineurin inhibitorinduced pain syndrome after allo-SCT. Bone Marrow Transplant 47:593595.

Kampa BM, Clements J, Jonas P, Stuart GJ (2004) Kinetics of $\mathrm{Mg}^{2+}$ unblock of NMDA receptors: implications for spike-timing dependent synaptic plasticity. J Physiol 556:337-345.

Kim S, Ziff EB (2014) Calcineurin mediates synaptic scaling via synaptic trafficking of $\mathrm{Ca}^{2+}$-permeable AMPA receptors. PLoS Biol 12:e1001900.

Krupp JJ, Vissel B, Thomas CG, Heinemann SF, Westbrook GL (2002) Calcineurin acts via the C-terminus of NR2A to modulate desensitization of NMDA receptors. Neuropharmacology 42:593-602.

Li DP, Chen SR, Pan YZ, Levey AI, Pan HL (2002) Role of presynaptic muscarinic and $\mathrm{GABA}(\mathrm{B})$ receptors in spinal glutamate release and cholinergic analgesia in rats. J Physiol 543:807-818.

Li L, Chen SR, Chen H, Wen L, Hittelman WN, Xie JD, Pan HL (2016) Chloride homeostasis critically regulates synaptic NMDA receptor activity in neuropathic pain. Cell Rep 15:1376-1383.

Lieberman DN, Mody I (1994) Regulation of NMDA channel function by endogenous $\mathrm{Ca}(2+)$-dependent phosphatase. Nature 369:235-239.

Liu H, Wang H, Sheng M, Jan LY, Jan YN, Basbaum AI (1994) Evidence for presynaptic N-methyl-D-aspartate autoreceptors in the spinal cord dorsal horn. Proc Natl Acad Sci USA 91:8383-8387.

Liu J, Farmer JD Jr, Lane WS, Friedman J, Weissman I, Schreiber SL (1991) Calcineurin is a common target of cyclophilin-cyclosporin A and FKBPFK506 complexes. Cell 66:807-815.

Luo Y, Ma H, Zhou JJ, Li L, Chen SR, Zhang J, Chen L, Pan HL (2018) Focal cerebral ischemia and reperfusion induce brain injury through alpha2delta-1-bound NMDA receptors. Stroke 49:2464-2472. 
Luo ZD, Chaplan SR, Higuera ES, Sorkin LS, Stauderman KA, Williams ME, Yaksh TL (2001) Upregulation of dorsal root ganglion (alpha)2(delta) calcium channel subunit and its correlation with allodynia in spinal nerve-injured rats. J Neurosci 21:1868-1875.

Ma H, Chen SR, Chen H, Zhou JJ, Li DP, Pan HL (2018) alpha2delta-1 couples to NMDA receptors in the hypothalamus to sustain sympathetic vasomotor activity in hypertension. J Physiol 596:4269-4283.

Marais E, Klugbauer N, Hofmann F (2001) Calcium channel alpha(2)delta subunits-structure and Gabapentin binding. Mol Pharmacol 59:12431248.

McGuinness L, Taylor C, Taylor RD, Yau C, Langenhan T, Hart ML, Christian H, Tynan PW, Donnelly P, Emptage NJ (2010) Presynaptic NMDARs in the hippocampus facilitate transmitter release at theta frequency. Neuron 68:1109-1127.

McRoberts JA, Ennes HS, Marvizon JC, Fanselow MS, Mayer EA, Vissel B (2011) Selective knockdown of NMDA receptors in primary afferent neurons decreases pain during phase 2 of the formalin test. Neuroscience 172:474-482.

Miletic G, Lippitt JA, Sullivan KM, Miletic V (2013) Loss of calcineurin in the spinal dorsal horn contributes to neuropathic pain, and intrathecal administration of the phosphatase provides prolonged analgesia. Pain 154:2024-2033.

Miletic G, Hermes JL, Bosscher GL, Meier BM, Miletic V (2015) Protein kinase $\mathrm{C}$ gamma-mediated phosphorylation of GluAl in the postsynaptic density of spinal dorsal horn neurons accompanies neuropathic pain, and dephosphorylation by calcineurin is associated with prolonged analgesia. Pain 156:2514-2520.

Mohapatra DP, Nau C (2005) Regulation of $\mathrm{Ca}^{2+}$-dependent desensitization in the vanilloid receptor TRPV1 by calcineurin and cAMP-dependent protein kinase. J Biol Chem 280:13424-13432.

Newton RA, Bingham S, Case PC, Sanger GJ, Lawson SN (2001) Dorsal root ganglion neurons show increased expression of the calcium channel alpha2delta-1 subunit following partial sciatic nerve injury. Brain Res Mol Brain Res 95:1-8.

Nishi H, Hashimoto K, Panchenko AR (2011) Phosphorylation in proteinprotein binding: effect on stability and function. Structure 19:1807-1815.

Noda Y, Kodama K, Yasuda T, Takahashi S (2008) Calcineurin-inhibitorinduced pain syndrome after bone marrow transplantation. J Anesth 22:61-63.

Pan YZ, Li DP, Pan HL (2002) Inhibition of glutamatergic synaptic input to spinal lamina II(o) neurons by presynaptic alpha(2)-adrenergic receptors. J Neurophysiol 87:1938-1947.

Park H, Popescu A, Poo MM (2014) Essential role of presynaptic NMDA receptors in activity-dependent BDNF secretion and corticostriatal LTP. Neuron 84:1009-1022.

Park KS, Mohapatra DP, Misonou H, Trimmer JS (2006) Graded regulation of the Kv2.1 potassium channel by variable phosphorylation. Science 313:976-979.

Rycroft BK, Gibb AJ (2004) Inhibitory interactions of calcineurin (phosphatase $2 \mathrm{~B}$ ) and calmodulin on rat hippocampal NMDA receptors. Neuropharmacology 47:505-514.

Snell GI, Westall GP, Paraskeva MA (2013) Immunosuppression and allograft rejection following lung transplantation: evidence to date. Drugs 73:1793-1813.

Strack S, Wadzinski BE, Ebner FF (1996) Localization of the calcium/ calmodulin-dependent protein phosphatase, calcineurin, in the hindbrain and spinal cord of the rat. J Comp Neurol 375:66-76.

Sulzer D, Pothos EN (2000) Regulation of quantal size by presynaptic mechanisms. Rev Neurosci 11:159-212.

Tanabe K (2003) Calcineurin inhibitors in renal transplantation: what is the best option? Drugs 63:1535-1548.
Tasoglu O, Gokcan H, Demir SO, Yenigun D, Akdogan M, Kacar S (2016) Pregabalin: a new adjunct in calcineurin inhibitor pain syndrome treatment. Prog Transplant 26:224-226.

Taylor CP, Garrido R (2008) Immunostaining of rat brain, spinal cord, sensory neurons and skeletal muscle for calcium channel alpha2-delta (alpha2-delta) type 1 protein. Neuroscience 155:510-521.

Tong G, Shepherd D, Jahr CE (1995) Synaptic desensitization of NMDA receptors by calcineurin. Science 267:1510-1512.

Udomkarnjananun S, Townamchai N, Virojanawat M, Avihingsanon Y, Praditpornsilpa K (2018) An unusual manifestation of calcineurin inhibitor-induced pain syndrome in kidney transplantation: a case report and literature review. Am J Case Rep 19:442-446.

Villaverde V, Cantalejo M, Balsa A, Mola EM, Sanz A (1999) Leg bone pain syndrome in a kidney transplant patient treated with tacrolimus (FK506). Ann Rheum Dis 58:653-654.

Wei X, Zhao M, Li Q, Xiao X, Zhu L (2018) Tacrolimus-induced pain syndrome after bone marrow transplantation: a case report and literature review. Transplant Proc 50:4090-4095.

Whitehouse G, Gray E, Mastoridis S, Merritt E, Kodela E, Yang JH, Danger R, Mairal M, Christakoudi S, Lozano JJ, Macdougall IC, Tree TI, Sanchez-Fueyo A, Martinez-Llordella M (2017) IL-2 therapy restores regulatory T-cell dysfunction induced by calcineurin inhibitors. Proc Natl Acad Sci USA 14:7083-7088.

Wu ZZ, Chen SR, Pan HL (2005) Transient receptor potential vanilloid type 1 activation down-regulates voltage-gated calcium channels through calcium-dependent calcineurin in sensory neurons. J Biol Chem 280:1814218151.

Wu ZZ, Chen SR, Pan HL (2006) Signaling mechanisms of down-regulation of voltage-activated $\mathrm{Ca}^{2+}$ channels by transient receptor potential vanilloid type 1 stimulation with olvanil in primary sensory neurons. Neuroscience 141:407-419.

Xie JD, Chen SR, Pan HL (2017) Presynaptic mGluR5 receptor controls glutamatergic input through protein kinase C-NMDA receptors in paclitaxel-induced neuropathic pain. J Biol Chem 292:20644-20654.

Xie JD, Chen SR, Chen H, Zeng WA, Pan HL (2016) Presynaptic N-methyld-aspartate (NMDA) receptor activity is increased through protein kinase C in paclitaxel-induced neuropathic pain. J Biol Chem 291:19364-19373.

Yamamoto T, Yaksh TL (1992) Spinal pharmacology of thermal hyperesthesia induced by constriction injury of sciatic nerve: excitatory amino acid antagonists. Pain 49:121-128.

Yan X, Jiang E, Gao M, Weng HR (2013) Endogenous activation of presynaptic NMDA receptors enhances glutamate release from the primary afferents in the spinal dorsal horn in a rat model of neuropathic pain. J Physiol 591:2001-2019.

Zhao YL, Chen SR, Chen H, Pan HL (2012) Chronic opioid potentiates presynaptic but impairs postsynaptic N-methyl-D-aspartic acid receptor activity in spinal cords: implications for opioid hyperalgesia and tolerance. J Biol Chem 287:25073-25085.

Zhou HY, Chen SR, Chen H, Pan HL (2010) Opioid-induced long-term potentiation in the spinal cord is a presynaptic event. J Neurosci 30:4460-4466

Zhou HY, Chen SR, Pan HL (2011) Targeting N-methyl-D-aspartate receptors for treatment of neuropathic pain. Expert Rev Clin Pharmacol 4:379-388.

Zhou HY, Chen SR, Byun HS, Chen H, Li L, Han HD, Lopez-Berestein G, Sood AK, Pan HL (2012) N-methyl-D-aspartate receptor- and calpainmediated proteolytic cleavage of $\mathrm{K}^{+}$-Cl- cotransporter-2 impairs spinal chloride homeostasis in neuropathic pain. J Biol Chem 287:33853-33864.

Zhou JJ, Li DP, Chen SR, Luo Y, Pan HL (2018) The alpha2delta-1-NMDA receptor coupling is essential for corticostriatal long-term potentiation and is involved in learning and memory. J Biol Chem 293:19354-19364. 